Article

\title{
First-Row-Transition Ion Metals(II)-EDTA Functionalized Magnetic Nanoparticles as Catalysts for Solvent-Free Microwave-Induced Oxidation of Alcohols
}

\author{
Nuno M. R. Martins ${ }^{1}$ (D), Luísa M. D. R. S. Martins ${ }^{1,2, *}$ (D), Carlos O. Amorim ${ }^{3}$, Vitor S. Amaral ${ }^{3}$ \\ and Armando J. L. Pombeiro ${ }^{1}$ \\ 1 Centro de Química Estrutural, Instituto Superior Técnico, Universidade de Lisboa, Av. Rovisco Pais, \\ 1049-001 Lisboa, Portugal; nunommartins@tecnico.ulisboa.pt (N.M.R.M.); \\ pombeiro@tecnico.ulisboa.pt (A.J.L.P.) \\ 2 Chemical Engineering Department, ISEL, Instituto Politécnico de Lisboa, R. \\ Conselheiro Emídio Navarro, 1959-007 Lisboa, Portugal \\ 3 Department of Physics and CICECO, University of Aveiro, 3810-193 Aveiro, Portugal; \\ amorim5@ua.pt (C.O.A.); vamaral@ua.pt (V.S.A.) \\ * Correspondence: lmartins@deq.isel.ipl.pt; Tel.: +351-218-419-264
}

Received: 16 October 2017; Accepted: 6 November 2017; Published: 9 November 2017

\begin{abstract}
A series of first-row transition-metals combined with ethylenediamine tetraacetic acid (EDTA), as metal-based $\mathrm{N}, \mathrm{O}$-chelating ligands, at the surface of ferrite magnetic nanoparticles (MNPs) was prepared by a co-precipitation method. Those EDTA functionalized MNPs with general formula $\mathrm{Fe}_{3} \mathrm{O}_{4} @ E D T A-\mathrm{M}^{2+}\left[\mathrm{M}=\mathrm{Mn}^{2+}(1), \mathrm{Fe}^{2+}(2), \mathrm{Co}^{2+}(3), \mathrm{Ni}^{2+}(4), \mathrm{Cu}^{2+}\right.$ (5) or $\mathrm{Zn}^{2+}$ (6)] were characterized by FTIR (Fourier Transform Infrared) spectroscopy, powder XRD (X-ray Diffraction), SEM (Scanning Electron Microscope), EDS (Energy Dispersive Spectrometer), VSM (Vibrating Sample Magnetometer) and TGA (Thermal Gravity Analysis). The application of the magnetic NPs towards the microwave-assisted oxidation of several alcohol substrates in a solvent-free medium was evaluated. The influence of reaction parameters such as temperature, time, type of oxidant, and presence of organic radicals was investigated. This study demonstrates that these MNPs can act as efficient catalysts for the conversion of alcohols to the corresponding ketones or aldehydes with high selectivity and yields up to $99 \%$ after $2 \mathrm{~h}$ of reaction at $110^{\circ} \mathrm{C}$ using $t-\mathrm{BuOOH}$ as oxidant. Moreover, they have the advantage of being magnetically recoverable catalysts that can be easily recycled in following runs.
\end{abstract}

Keywords: alcohol oxidation; ferrite magnetic nanoparticles; transition metals; magnetic recovery; functionalized nanoparticles; microwave irradiation; solvent-free

\section{Introduction}

Fine chemistry products, such as agro-chemicals, drugs and fragrances, require ketones and/or aldehydes as starting materials, which can be obtained by oxidation of alcohols [1-3]. Nowadays it is imperative to convert alcohol substrates into the desired more oxidized forms, to fulfill the demand of the market, in a sustainable manner. The oxidative chemical process should not generate large amounts of waste materials or use hazardous oxidizing agents and should occur in a catalytic-mediated system [4-7]. Hence, it is also highly desirable to develop cheap catalysts.

Heterogeneous catalytic systems tend to be a better alternative to homogeneous ones, since an active and stable catalyst in a different physical phase can be more easily recovered from the reaction medium and reused. In the homogeneous systems, this feature is harder to achieve constituting a 
major drawback [8-10]. Even in heterogeneous catalytic systems the recovery of the catalyst can present handicaps. Significant quantity losses of the desired materials (catalyst and/or products) can occur using the most common well-established separation procedures such as centrifugation and filtration. In addition, serious limitations are encountered in applying traditional separation methods to the recovery of nanocatalysts (size range below $100 \mathrm{~nm}$ ) [8]. Ultra-centrifugation can mitigate these limitations, but represents a significant extra cost.

In order to overcome some separation issues and reduce operational costs, magnetic nanoparticle-supported catalysts have been studied. Advantages in using these materials rely mainly on the high accessible surface area (increase of active sites/weight of catalyst) and the easy separation with the usage of an external magnet. Magnetic nanoparticles like magnetite $\left(\mathrm{Fe}_{3} \mathrm{O}_{4}\right)$ have been explored due to such advantages and its simple and cheap preparation protocol [11-14]. In addition, a gain or enhancement of physical-chemical properties can be achieved by functionalizing the surface of magnetite, introducing new compounds such as gum Arabic [15], chitosan [16], humic acid [17] or diethylenetriamine [18]. The common coating of magnetite with carbon and silica offers higher mechanic and thermal stability, and allows the incorporation of active species on the modified surface [19-25]. Functionalized magnetic catalysts can exhibit comparable (and sometimes even enhanced) activity with that of their corresponding homogeneous analogues [26].

Recently, the preparation of magnetite coated with ethylenediamine tetraacetic acid (EDTA) to be used as nano-adsorbent for the removal of $\mathrm{Cu}$ (II) from aqueous solution [27] and of $\mathrm{Fe}_{3} \mathrm{O}_{4} @$ EDTA-Cu(II) magnetic nanoparticles (MNPs) as catalysts for direct oxidative amidation of alcohols [28] and oxidative coupling of formamides with $\beta$-dicarbonyl compounds [29] has been reported.

To our knowledge, EDTA functionalized magnetite type MNPs have not been studied towards oxidation of alcohols. In addition, microwave (MW) irradiation heating which constitutes an appealing alternative energy source (generating heat evenly throughout the reactor) enhancing product purity, selectivity, and yield as well as being more energy efficient and economical in comparison to conventional heating methods has not been applied on such MNPs type [6,30,31]. Moreover, ferrite-type materials have shown absorption for MW frequencies contributing to better catalytic performances $[14,32]$. Therefore, the investigation of the catalytic performance of magnetite surface functionalized materials for MW-assisted oxidation of alcohols is of great significance.

Herewith, we report the preparation of a series of first-row transition-metal (coordinated via $\mathrm{N}, \mathrm{O}$-moieties of EDTA) with modified surface of magnetite MNPs and their application as reusable catalysts for the selective oxidation of alcohols into the corresponding aldehydes or ketones in an added solvent-free medium using $t-\mathrm{BuOOH}$ as oxidant. This easy protocol overcomes some problems of homogeneous and conventional heterogeneous conditions. The easy removal of the catalyst makes the procedure very simple and eco-friendly.

\section{Results}

\subsection{Catalysts Characterization}

\subsubsection{FT-IR Spectra}

The 1-6 MNPs FTIR (Infrared Spectroscopy) spectra were recorded (Figure S1 in Supplementary Materials) and in Figure 1 we depict those of magnetite $\left(\mathrm{Fe}_{3} \mathrm{O}_{4}\right)$, magnetite coated with EDTA $(\mathbf{0})$ and magnetite surface functionalized with complex of EDTA- $\mathrm{Mn}^{2+}(\mathbf{1})$ MNPs. The common bands below $600 \mathrm{~cm}^{-1}$ are due to the spinel structure and peaks around $565 \mathrm{~cm}^{-1}$ correspond to the intrinsic vibrations of octahedral coordinated metal ions in the spinel structure (MNPs Fe-O stretching vibration) [13,14]. The broad band at ca. $3400 \mathrm{~cm}^{-1}$ and that at ca. $1631 \mathrm{~cm}^{-1}$ reveal the presence of hydroxyl groups.

In the 0 MNPs spectrum the broadening of the signal near $3000 \mathrm{~cm}^{-1}$ is ascribed to the $\mathrm{C}-\mathrm{H}$ stretching. The enhancement of the peak at $1620 \mathrm{~cm}^{-1}$ and the presence of small signals at ca. $1100-1000 \mathrm{~cm}^{-1}$ 
concern the $\mathrm{C}=\mathrm{O}$ and $\mathrm{C}-\mathrm{N}$ stretching, respectively. This proves the EDTA functionalized surface of the MNPs [27].

The fact that the dication metal ion $\left(\mathrm{Mn}^{2+}\right.$ in spectrum (1) of Figure 1) interacts with the organic moiety at the surface of magnetite results in the shifting of the $\mathrm{C}=\mathrm{O}$ vibration $\left(1462 \mathrm{~cm}^{-1}\right)$. The presence of the peak at $866 \mathrm{~cm}^{-1}$ suggests the COO-metal complex formation [28].

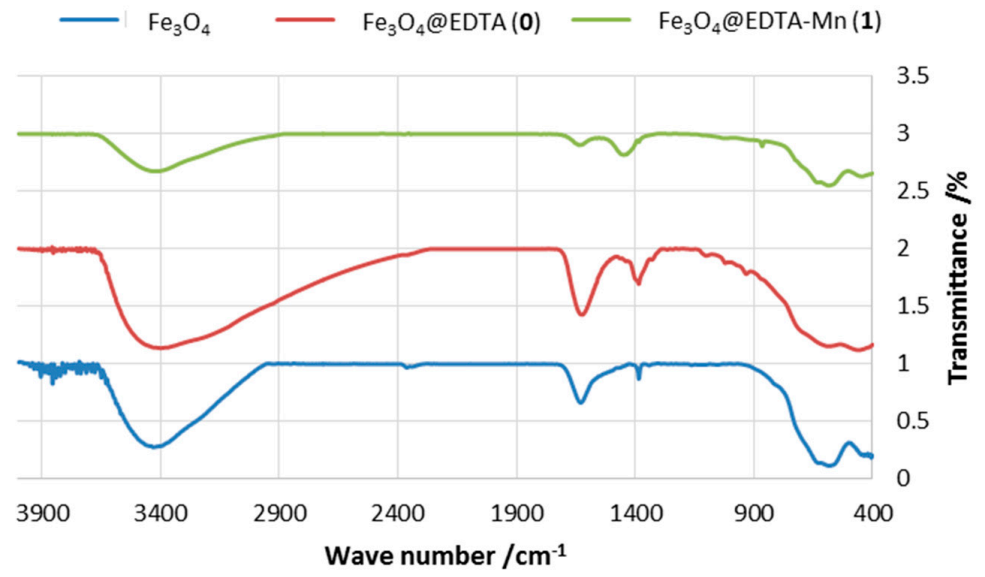

Figure 1. FT-IR (Fourier Transform Infrared) spectra of $\mathrm{Fe}_{3} \mathrm{O}_{4}, \mathrm{Fe}_{3} \mathrm{O}_{4} @ E D T A(0)$ and $\mathrm{Fe}_{3} \mathrm{O}_{4} @ E D T A-\mathrm{Mn}^{2+}$ (1) MNPs in the range of 4000 and $400 \mathrm{~cm}^{-1}$.

\subsubsection{XRD}

XRD (X-ray Diffraction Pattern) pattern of $\mathrm{Fe}_{3} \mathrm{O}_{4}, \mathrm{Fe}_{3} \mathrm{O}_{4} @ E D T A(0)$ and 1 MNPs are shown in Figure 2. 1 MNPs XRD pattern was taken as a representative example of 1-6 (Figure S2, Supplementary Materials) to evidence that the phase of the pure magnetite with a spinel structure with the EDTA-metal complex functionalized surface is not changed. The angle position and relative intensity of all diffraction peaks matched with crystalline magnetite spinel structure (JCPDS 75-1609) and are also in agreement with previous reports $[13,28]$. The six lattice planes of magnetite at $2 \theta 30.2^{\circ}(220), 35.4^{\circ}\left(\begin{array}{lll}3 & 1 & 1\end{array}\right)$,

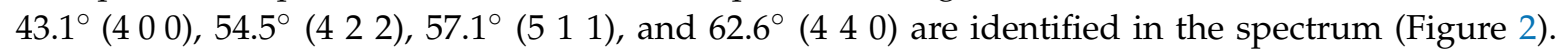
The organic amorphous material at the surface of the MNPs can be detected by the presence of wide peaks $\left(\right.$ ca. $2 \theta=18^{\circ}$ ).

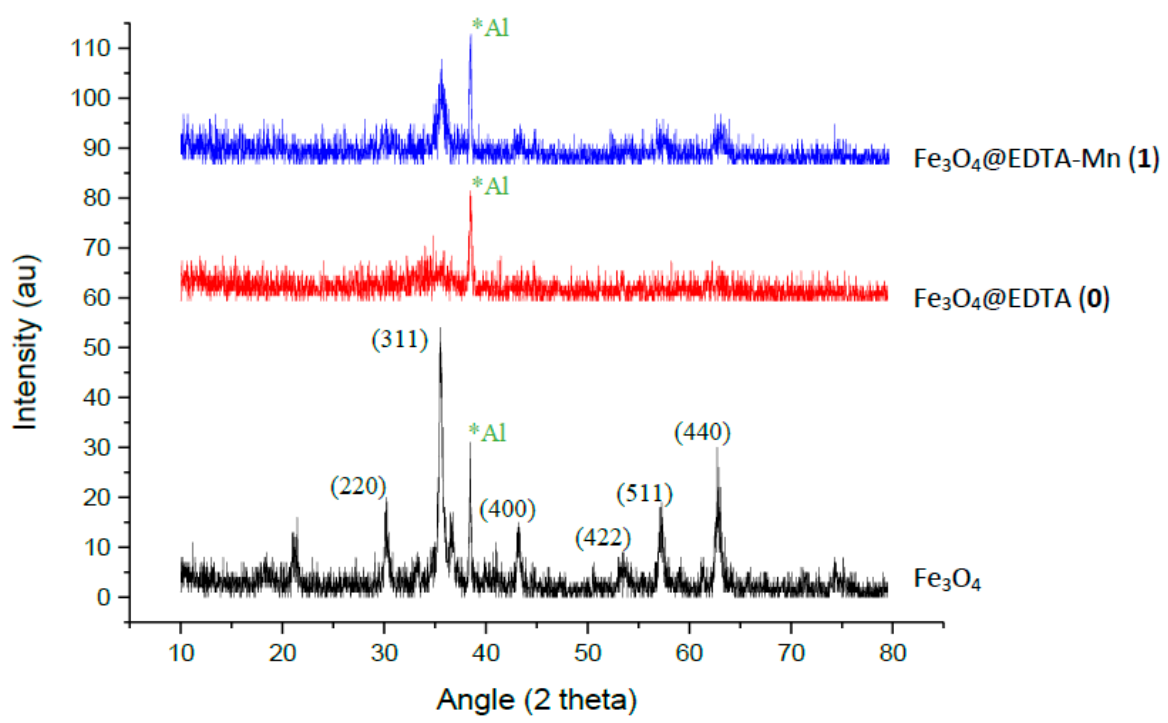

Figure 2. X-ray diffraction patterns of $\mathrm{Fe}_{3} \mathrm{O}_{4}, \mathrm{Fe}_{3} \mathrm{O}_{4} @$ EDTA (0) and $\mathrm{Fe}_{3} \mathrm{O}_{4} @$ EDTA-Mn ${ }^{2+}(\mathbf{1})$ MNPs. 
Average crystallite size of magnetite $(18 \mathrm{~nm})$ and 1-6 MNPs $(6-8 \mathrm{~nm})$ was determined by considering the full width at half-maximum (FWHM) of diffraction based on Scherrer equation with XRD data $(D=0.94 \lambda /(\beta \cos \theta)$, where $D$ is the average particle size of the crystallites, $\lambda$ is the incident wavelength, $\theta$ is the Bragg angle and $\beta$ is the diffracted full width at half maximum (in radians) caused by crystallization).

\subsubsection{TEM and SEM-EDS (Scanning Electron Microscopy-Energy Dispersive X-ray Spectroscopy}

Representative TEM (Transmission Electron Microscopy) and SEM micrographs of magnetite NPs and 0-6 MNPs are shown in Figure 3. The micrographs exhibit nanocrystalline irregular spherical shapes for all prepared materials with a lower primary size range ( 3 to $15 \mathrm{~nm}$ ) regarding the 0-6 MNPs in comparison to magnetite $(10$ to $30 \mathrm{~nm})$. It is clear the aggregation grade of all materials, which is an effect of the co-precipitation method used for the preparation of these MNPs [28]. Comparison between TEM and SEM data leads to conclude that particle aggregation effect is more pronounced in magnetite particles due their magnetic properties. The coated surface with the EDTA (0) seems to inhibit the aggregation effect, which results in an increased roughness at the surface (lower size semi-spherical particles). Similar morphology in 1-6 MNPs can be found. EDS results confirm that the samples contain $\mathrm{Mn}, \mathrm{Fe}, \mathrm{C}$ and $\mathrm{O}$ for $\mathbf{1}, \mathrm{Fe}, \mathrm{C}$ and $\mathrm{O}$ for $2, \mathrm{Co}, \mathrm{Fe}, \mathrm{C}$ and $\mathrm{O}$ for 3, Ni, Fe, $\mathrm{C}$ and $\mathrm{O}$ for 4, Cu, Fe, C and O for 5, Zn, Fe, C and O for 6 (Figures S3-S9 and Tables S1-S7, Supplementary Materials). $\mathrm{C}$ and $\mathrm{N}$ elements were not detectable (low quantity) by the SEM equipment constituting a limitation. The atomic percent of the immobilized transition metal at the surface of the 3-5 MNPs was ca. $3 \%$ and for 1 and 6 ca. $4 \%$ and 7\%, respectively. Regarding 2 MNPs, it is not possible to distinguish between the iron atoms from the core and those on the surface (attached to the organic moieties). Mapping experiments of 1 and 5 MNPs are presented in Figure 4, suggesting that the corresponding transition metal ions are present at the surface of the MNPs in a well-distributed way and uniform density/concentration.
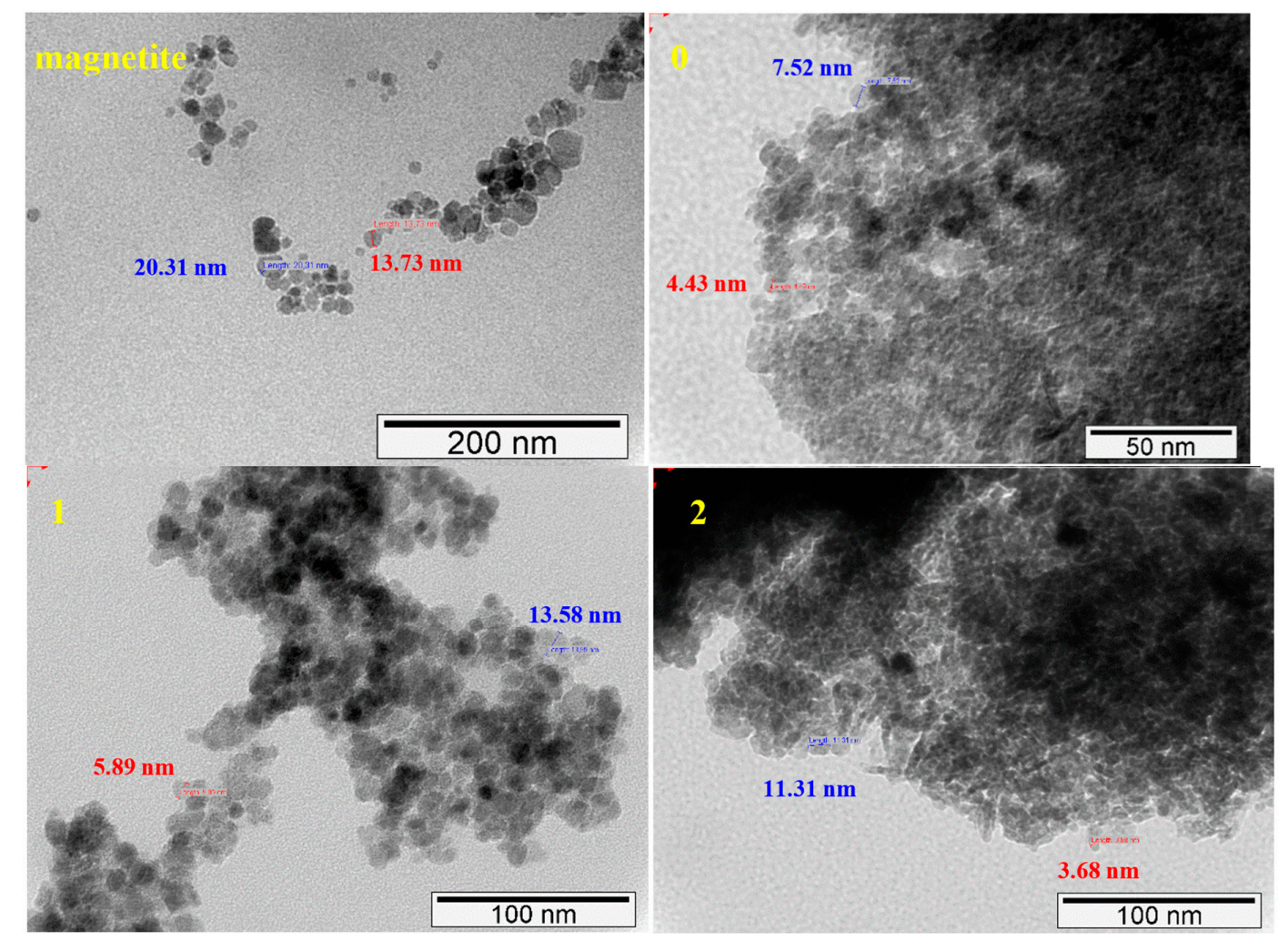

Figure 3. Cont. 

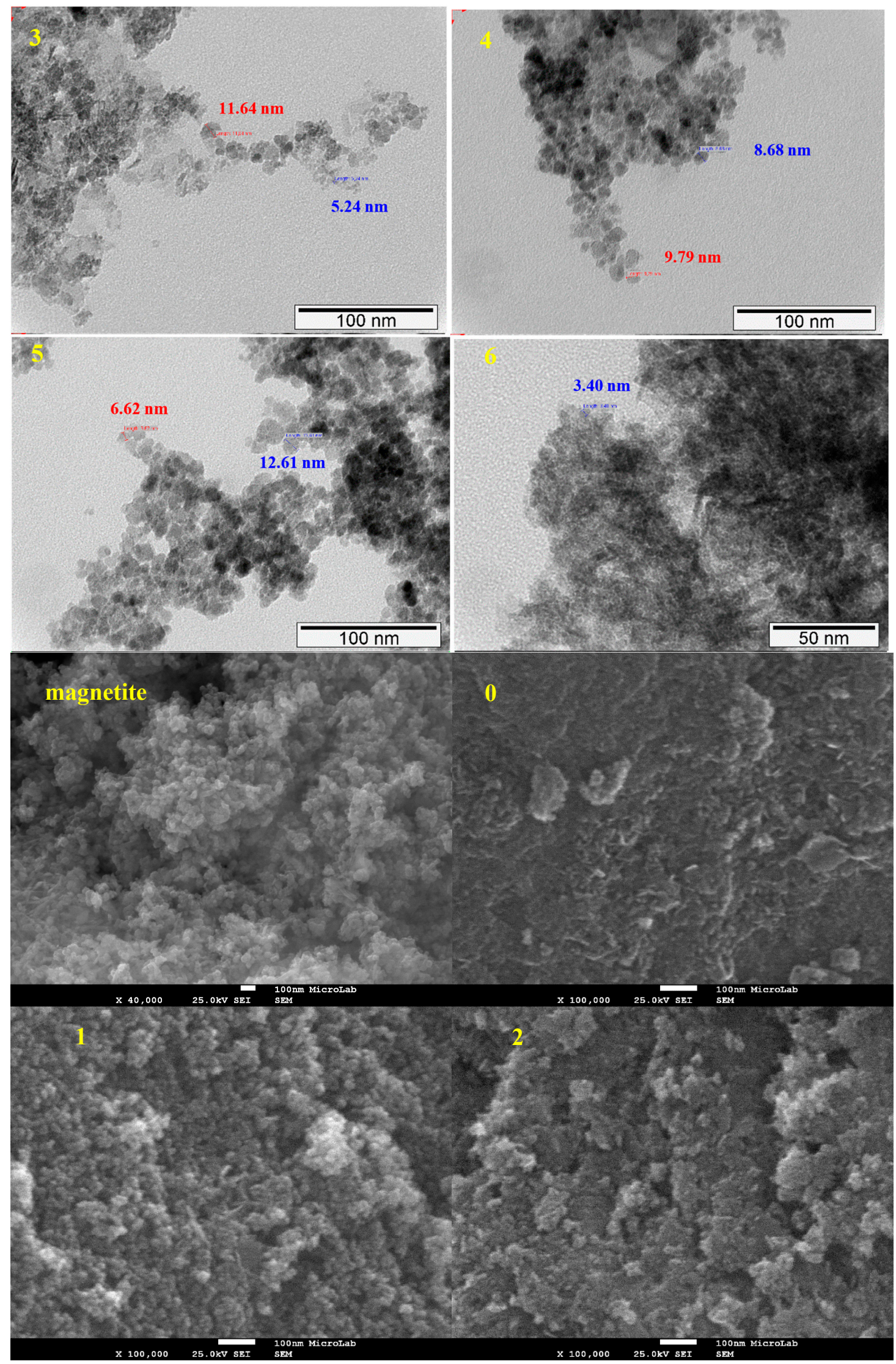

Figure 3. Cont. 


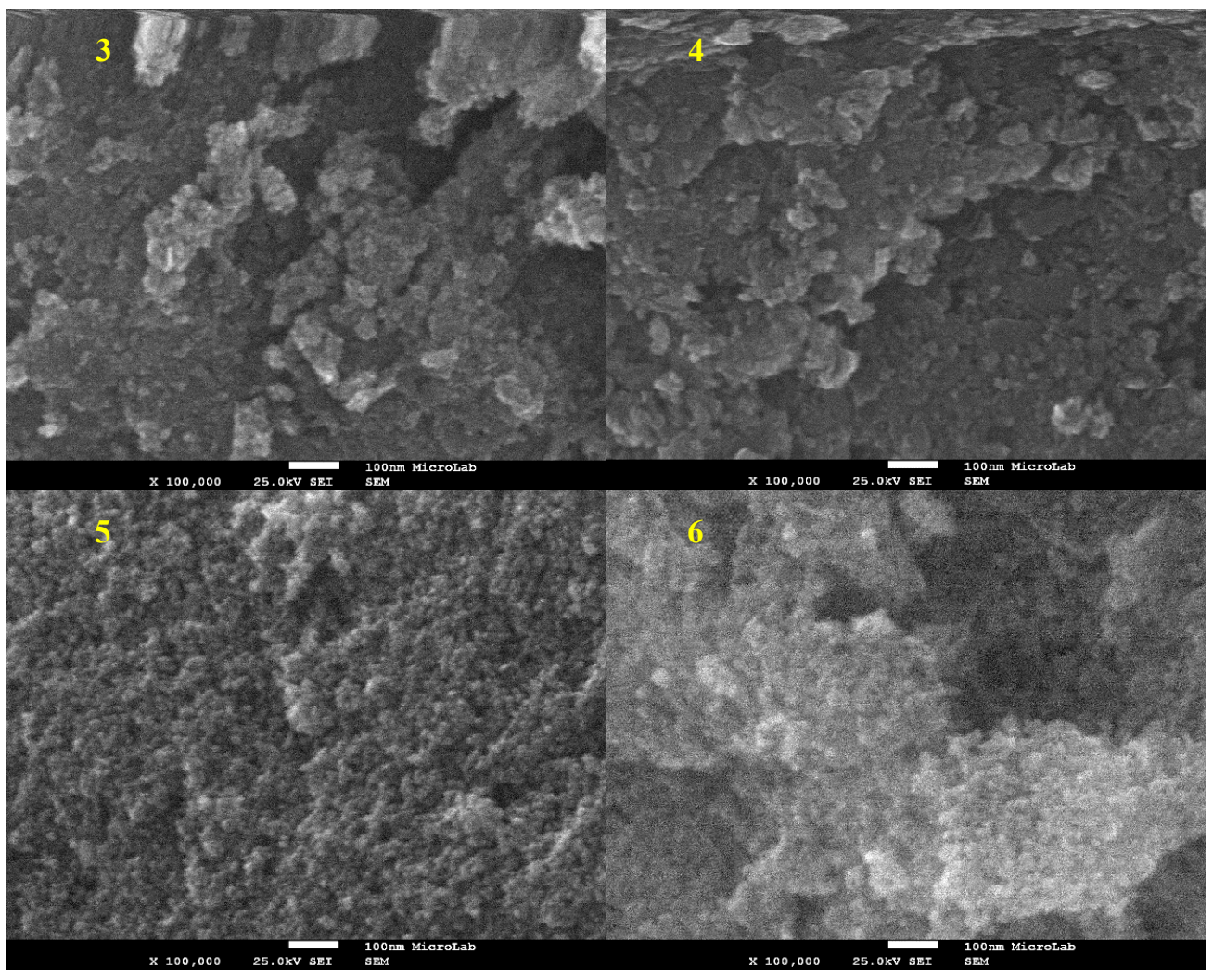

Figure 3. TEM (top) and SEM (bottom) micrographs of $\mathrm{Fe}_{3} \mathrm{O}_{4}, \mathrm{Fe}_{3} \mathrm{O}_{4} @ E D T A(0)$ and $\mathrm{Fe}_{3} \mathrm{O}_{4} @ E D T A-M^{2+}$ $\left[\mathrm{M}^{2+}=\mathrm{Mn}^{2+}(1), \mathrm{Fe}^{2+}(2), \mathrm{Co}^{2+}(3), \mathrm{Ni}^{2+}(4), \mathrm{Cu}^{2+}(5), \mathrm{Zn}^{2+}(6)\right] \mathrm{MNPs}$.

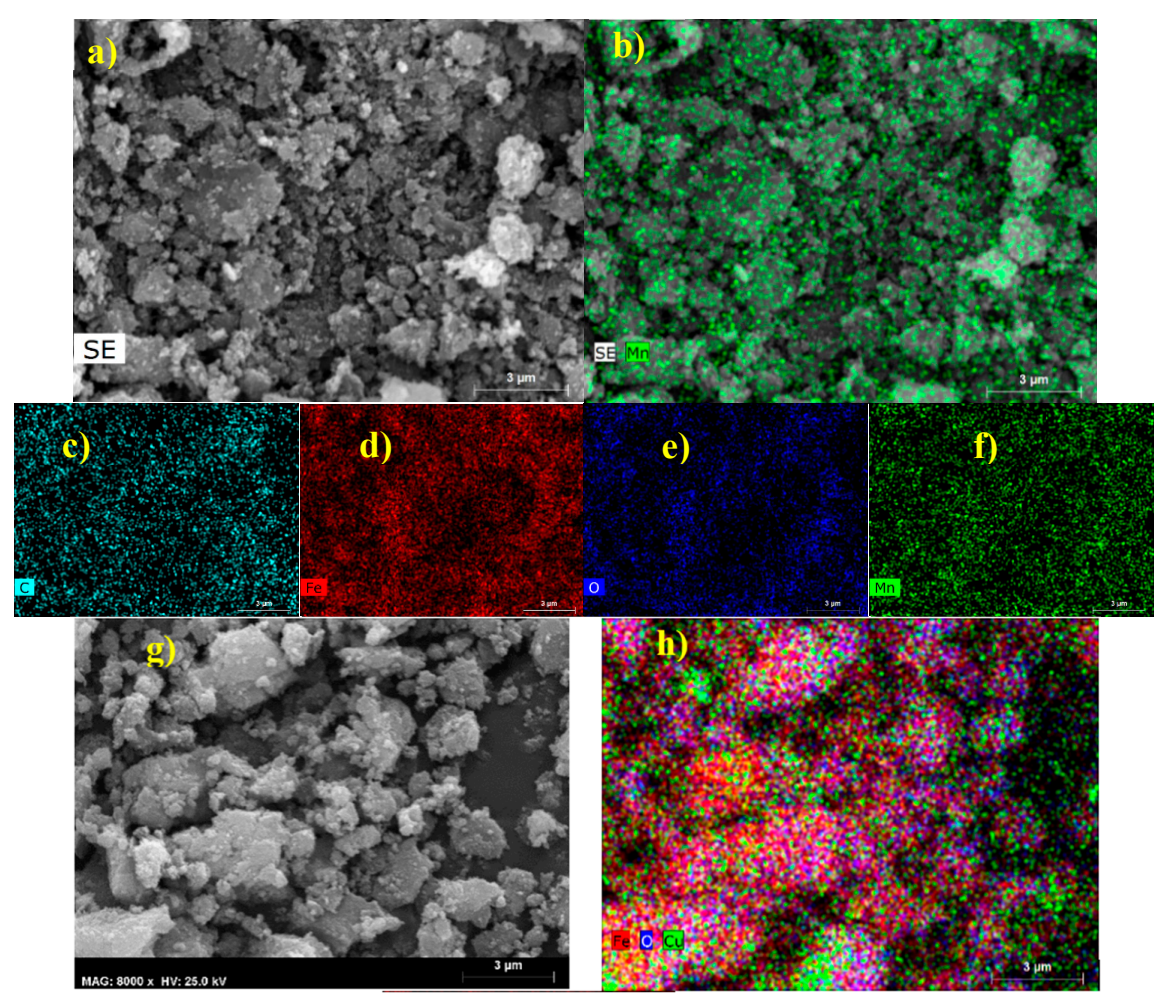

Figure 4. Cont. 

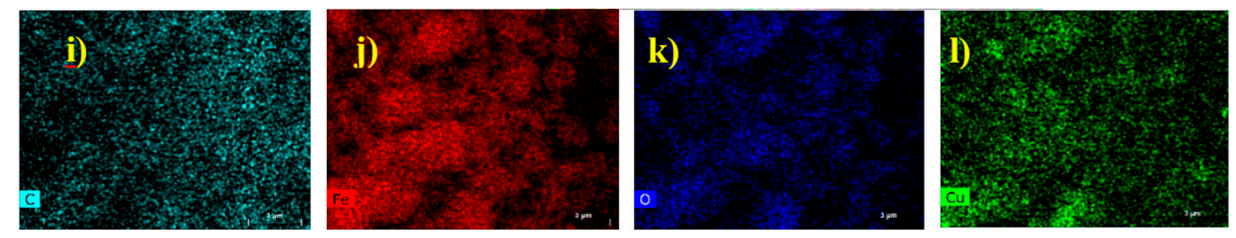

Figure 4. SEM mapping experiments on $\mathrm{Fe}_{3} \mathrm{O}_{4}$ @EDTA-Mn ${ }^{2+}$ (1) MNPs: (a) raw micrograph; (b) overlap of the raw micrograph with Mn element detection; (c) C element detection; (d) Fe element detection; (e) O element detection; (f) Mn element detection. SEM mapping experiments on $\mathrm{Fe}_{3} \mathrm{O}_{4} @ E D T A-\mathrm{Cu}^{2+}$

(5) MNPs; (g) raw micrograph; (h) overlap of $\mathrm{Fe}, \mathrm{O}$ and $\mathrm{Cu}$ elements detection; (i) $\mathrm{C}$ element detection;

(j) Fe element detection; (k) O element detection; (1) Cu element detection.

\subsubsection{TGA (Thermal Gravimetric Analysis)}

Features of the thermal stability of magnetite, $\mathrm{Fe}_{3} \mathrm{O}_{4} @ E D T A(\mathbf{0})$ and $\mathrm{Fe}_{3} \mathrm{O}_{4} @ E D T A-\mathrm{Mn}^{2+}(\mathbf{1})$ MNPs are illustrated in Figure 5. Magnetite $\left(\mathrm{Fe}_{3} \mathrm{O}_{4}\right)$ exhibits thermal stability up to $220{ }^{\circ} \mathrm{C}$. However, in the temperature range of $220-300{ }^{\circ} \mathrm{C}$ it shows a weigh loss of ca. $2 \%$, mainly due to the loss of residual water [27] or likely due to the formation of a crystallized $\mathrm{Fe}_{3} \mathrm{O}_{4}$ phase and the phase transformation from cubic $\mathrm{Fe}_{3} \mathrm{O}_{4}$ to tetragonal [33], resulting in the released of lattice oxygen. 0 MNPs revealed a significant weight loss of ca. $17 \%$ from 80 to $330{ }^{\circ} \mathrm{C}$ that corresponds to the decomposition of the organic structure made of molecules of EDTA. Above $350^{\circ} \mathrm{C}$ there is no considerable change of weight, which implies that only the iron oxide core $\left(\mathrm{Fe}_{3} \mathrm{O}_{4}\right)$ remains at this stage. This behavior is indicative that the organic moieties of EDTA are indeed incorporated at the surface of $\mathrm{Fe}_{3} \mathrm{O}_{4} \mathrm{MNPs}$. The weight loss pattern of $\mathbf{1}$ MNPs shows a partial decomposition of the organic moiety from 80 to $330{ }^{\circ} \mathrm{C}$ corresponding to ca. $8 \%$ mass loss. The temperature range of 330 to $520{ }^{\circ} \mathrm{C}$ (weight percentage of ca. $4 \%$ ) concerns the formation of manganese oxide. Above $520^{\circ} \mathrm{C}$ the weight loss pattern reaches a plateau, which is indicative that only iron and manganese oxides are present. Similar behavior was found for 2-6 MNPs (Figure S10, Supplementary Materials).

- $\mathrm{Fe}_{3} \mathrm{O}_{4}$

- $\mathrm{Fe}_{3} \mathrm{O}_{4} @ E \mathrm{EDTA}(0)$

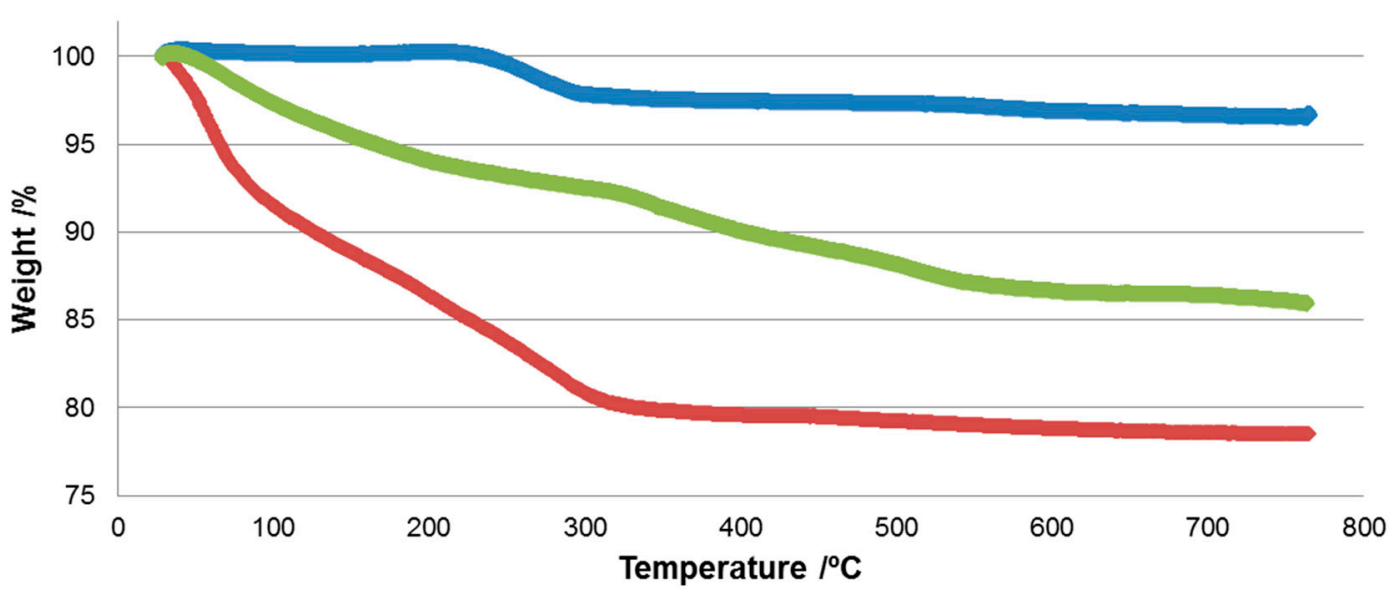

Figure 5. Thermogravimetric curves of $\mathrm{Fe}_{3} \mathrm{O}_{4}$ (magnetite), $\mathrm{Fe}_{3} \mathrm{O}_{4} @ E D T A(0)$ and $\mathrm{Fe}_{3} \mathrm{O}_{4} @ E D T A-\mathrm{Mn}^{2+}$ (1) MNPs.

SEM mapping and TGA analysis prove the high level of coating of the Mn(II)-EDTA complex on the MNPs. 


\subsubsection{VSM (Vibrating Sample Magnetometry)}

The magnetic properties of 0-6 MNPs were studied by VSM at room temperature. Figure 6 presents the magnetization as a function of applied field (Oe) the full field range $-100<\mathrm{H}<100 \mathrm{kOe}$ at $300 \mathrm{~K}$. Mass normalization is by total sample mass. To compare the surface modification influence on the magnetic properties of 0-6 MNPs, magnetite MNPs were also measured.

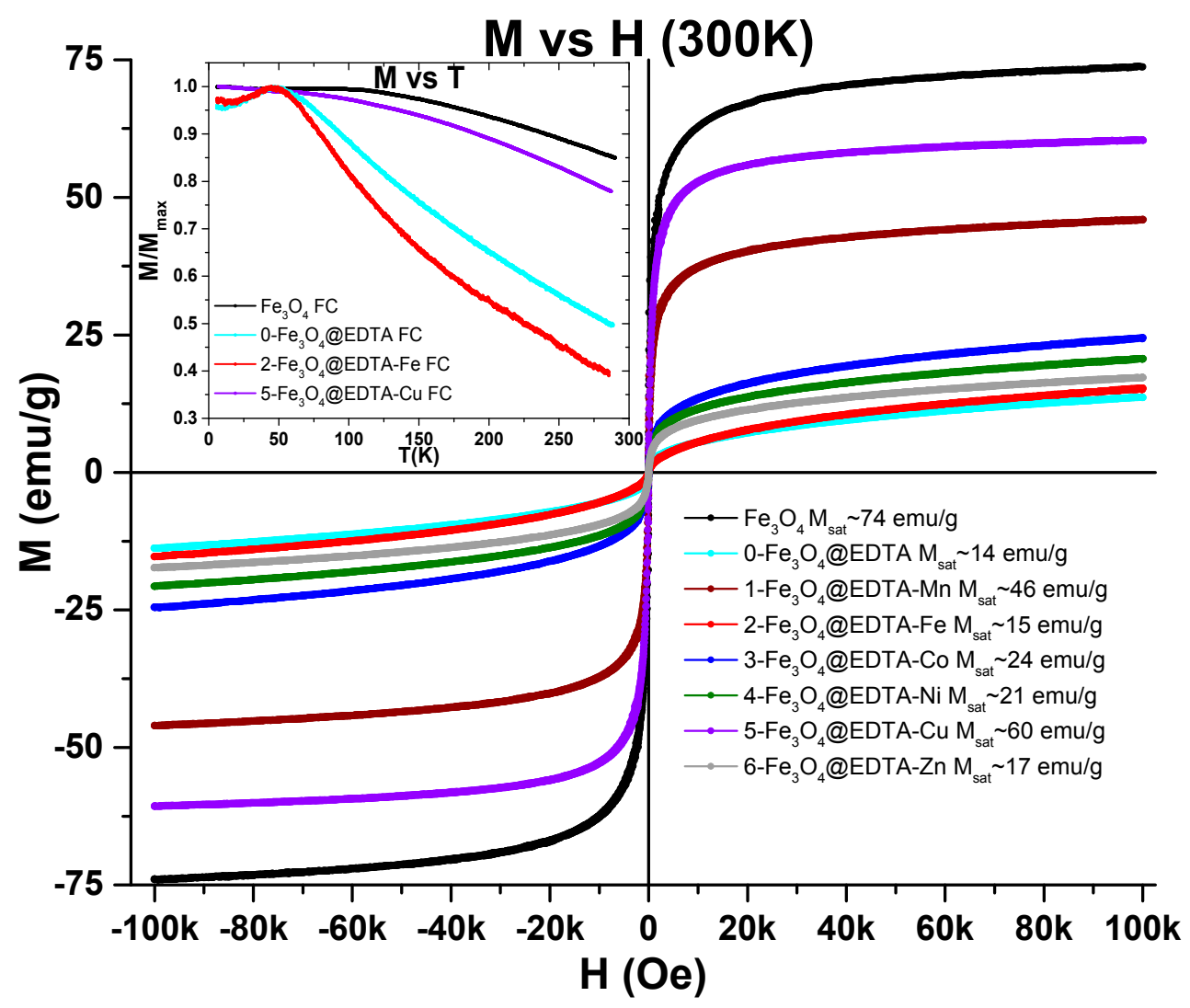

Figure 6. Magnetization curve at $\mathrm{T}=300 \mathrm{~K}$ as a function of magnetic field on $\mathrm{Fe}_{3} \mathrm{O}_{4}, \mathrm{Fe}_{3} \mathrm{O}_{4} @ \mathrm{EDTA}(\mathbf{0})$, $\mathrm{Fe}_{3} \mathrm{O}_{4} @ E D T A-M^{2+}\left[\mathrm{M}^{2+}=\mathrm{Mn}^{2+}(\mathbf{1}), \mathrm{Fe}^{2+}(2), \mathrm{Co}^{2+}(3), \mathrm{Ni}^{2+}(4), \mathrm{Cu}^{2+}(5), \mathrm{Zn}^{2+}(6)\right]$ MNPs. Inset shows the magnetization curve (normalized by its maximum) as a function of the temperature for $\mathrm{Fe}_{3} \mathrm{O}_{4}, \mathbf{0}$, 2 and 5 MNPs under a field 300 Oe. Samples with lower magnetizations present superparamagnetic behavior above a blocking temperature of $\sim 50 \mathrm{~K}$.

As expected, magnetite revealed a high saturation magnetization (Ms) of $74 \mathrm{emu} / \mathrm{g}$, while this value is significantly lower for 0 MNPs $(14 \mathrm{emu} / \mathrm{g})$. MNPs 1-6 show a wide range of saturation magnetizations (15-60 emu/g). One should remark that the mass normalization in Figure 6 relates to the total mass of the samples, including EDTA coating. Since this amounts to about $17 \%$ or less of the mass, this is not the main factor for the observed reduction of the normalized magnetization.

One can identify two families of behavior by observation of the curvature of $\mathrm{M}$ vs. $\mathrm{H}$ curves of the MNPs. Magnetite, 1 and $\mathbf{5}$ MNPs present a fast initial increase of magnetization and higher curvature on the approach to magnetic saturation. This leads to the highest saturation values $(74,46$ and $60 \mathrm{emu} / \mathrm{g}$ respectively). The remaining five MNPs, with the lowest saturation magnetizations (14-24 emu/g), present a much smother curvature on the $\mathrm{M}$ vs. H curves, suggesting a Langevin function like behavior, characteristic of a superparamagnetic state.

This distinction is further supported by the temperature dependence of the magnetization measured at a small $\mathrm{H}$ of 300 Oe (on heating), for which representative results are presented in the inset of Figure 6, normalized by each individual maximum value. From the first family (magnetite 
and $5 \mathrm{MNPs}$ ), both show a M vs. T curve compatible with the ferrimagnetic behavior of magnetite, with a monotonous decrease, with negative curvature. The second family has a more complex behavior, with the typical superparamagnetic positive curvature (magnetization proportional to inverse temperature) above a blocking temperature around $50 \mathrm{~K}$ where a maximum is clearly observed.

However, irrespective of the main type of behavior, all MNPs present negligible magnetic hysteresis, with very small coercive magnetic fields $(\mathrm{Hc}<5 \mathrm{Oe})$ so that magnetic agglomeration effects are very small, as in superparamagnetic state.

It is interesting to notice that by the co-precipitation method, the formation of the magnetite core and the EDTA coating taking place simultaneously brings the EDTA interference in the crystallization step of iron oxide nanoparticles $\left(\mathrm{Fe}_{3} \mathrm{O}_{4} @\right.$ EDTA had lower magnetization as compared with that of bare $\mathrm{Fe}_{3} \mathrm{O}_{4}$ ). Such differences may be accounted by changes in the size of the individual MNPs. Saturation of magnetization decreases as particle sizes are reduced due to enhancement of the surface spin effects. Moreover, as particle size decreases the coercivity vanishes and the MNPs present a superparamagnetic state at room temperature [28].

Summarizing, all MNPs exhibit nearly superparamagnetic behavior, with magnetization saturation values high enough and coercive fields low enough to easy manipulate the MNPs with a conventional external magnet, as it is illustrated in Figure 7 for 1 MNPs. In the end of the alcohol oxidation. 1-6 MNPs can be magnetically collected together from the reaction solution. Then those MNPs can be washed and transferred to a new reaction medium and re-dispersed with a slightly shake to catalyze once more a new reaction run.
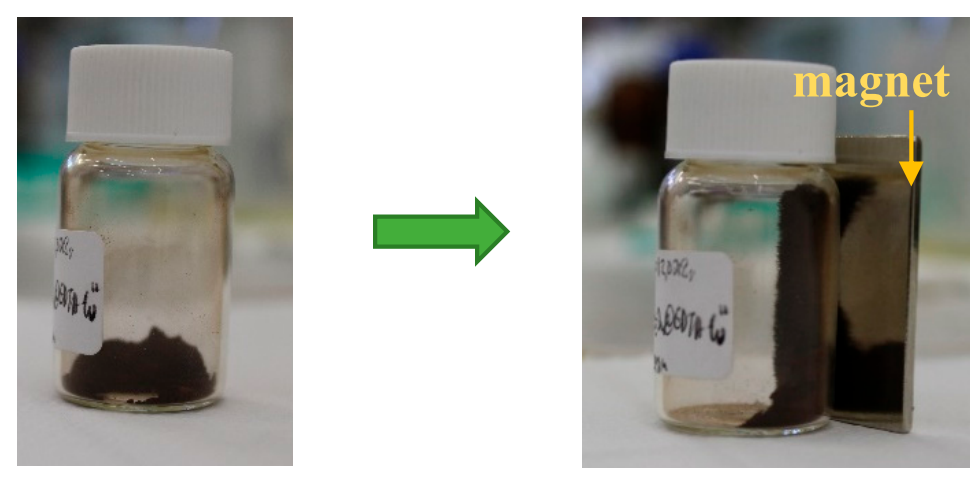

Figure 7. Magnetic manipulation of $\mathrm{Fe}_{3} \mathrm{O}_{4} @ E D T A-\mathrm{Mn}^{2+}(\mathbf{1})$ MNPs using an external magnet.

\subsection{Catalytic Performance}

The 0-6 NPs were tested as catalysts for the MW-assisted oxidation of alcohols with $t$ - $\mathrm{BuOOH}$ in an added solvent-free medium. With the growing concern to bring out a more environmentally friendly chemical process, the use of a solvent-free synthetic protocol is of great significance. In addition, the heating mode through MW irradiation that requires low power and possibility to enhance the activity of alcohol oxidation reactions $[6,7,14,34-41]$ is a feature to take into account. In order to find the optimized reaction conditions, 1-phenylethanol was selected as a model alcohol substrate to oxidize (Scheme 1). $t$ - $\mathrm{BuOOH}$ was used as the oxidant (chosen because it is a powerful oxidant among peroxidants and in view of the low hazardous grade of the formed by-product tert-butyl alcohol). Typically, reactions were performed with a $t$ - $\mathrm{BuOOH} / 1$-phenylethanol molar ratio of 2:1, under $10 \mathrm{~W}$ MW irradiation, at $80^{\circ} \mathrm{C}$, for $0.5 \mathrm{~h}$. In all the experiments 1-phenylethanol was oxidized to the corresponding ketone (acetophenone) in a selective manner (>99\%). 


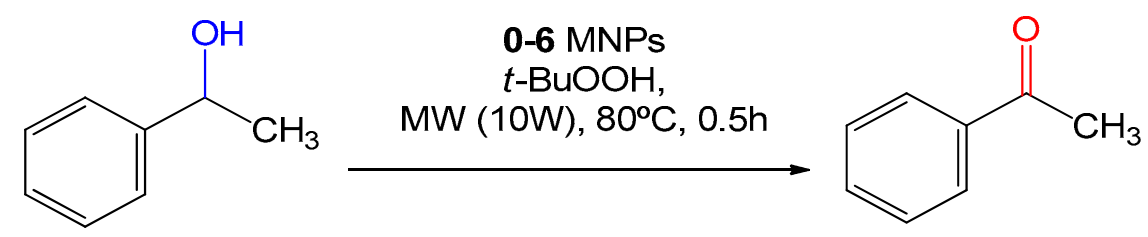

Scheme 1. Solvent-free MW-assisted peroxidation of 1-phenylethanol to acetophenone in the presence $t$-BuOOH using 0-6 MNPs as catalysts.

In order to select the best catalyst among the prepared 1-6 MNPs to focus our attention on the following reaction parameters studies, a quick reaction screening was performed and the results are illustrated in Table 1 . In the absence of any catalyst only $2 \%$ residual conversion of 1-phenylethanol to acetophenone was recorded (Table 1, entry 1). Using organic coated magnetite $\mathbf{0}$ MNPs as catalyst yielded $6.5 \%$ of acetophenone (Table 1 , entry 2 ). Under the same reaction conditions the activity of the metal-EDTA complex functionalized catalysts, 1-6 MNPs, were screened. From these results, 1, 3 and 5 (entries 3,5 and 7, respectively) were identified as the most active catalysts among the prepared MNPs. Hence, we focused our study using 1, 3 and 5 MNPs as catalysts.

Table 1. Solvent-free MW-assisted oxidation of 1-phenylethanol to acetophenone in the absence and presence of 0-6 MNPs as catalysts ${ }^{\text {a }}$. MW: microwave.

\begin{tabular}{|c|c|c|c|}
\hline Entry & Catalyst & $\mathrm{m} / \mathrm{mg}$ & Yield $\mathrm{b} / \%$ \\
\hline 1 & none & - & 1.7 \\
\hline 2 & $\mathrm{Fe}_{3} \mathrm{O}_{4} @ \operatorname{EDTA}(\mathbf{0})$ & 30.1 & 6.5 \\
\hline 3 & $\mathrm{Fe}_{3} \mathrm{O}_{4} @$ EDTA-Mn ${ }^{2+}(\mathbf{1})$ & 29.1 & 27.4 \\
\hline 4 & $\mathrm{Fe}_{3} \mathrm{O}_{4} @ \mathrm{EDTA}_{-} \mathrm{Fe}^{2+}(2)$ & 29.9 & 10.5 \\
\hline 5 & $\mathrm{Fe}_{3} \mathrm{O}_{4} @ E D T A-\mathrm{Co}^{2+}(3)$ & 29.8 & 31.1 \\
\hline 6 & $\mathrm{Fe}_{3} \mathrm{O}_{4} @ E D T A-\mathrm{Ni}^{2+}(4)$ & 30.0 & 7.2 \\
\hline 7 & $\mathrm{Fe}_{3} \mathrm{O}_{4} @ E D T A-\mathrm{Cu}^{2+}(5)$ & 30.0 & 14.3 \\
\hline 8 & $\mathrm{Fe}_{3} \mathrm{O}_{4} @ E D T A-\mathrm{Zn}^{2+}(6)$ & 29.9 & 7.0 \\
\hline
\end{tabular}

a Reaction conditions: 1-phenylethanol $(2.5 \mathrm{mmol}), t-\mathrm{BuOOH}$ aq. $70 \%(5.0 \mathrm{mmol}), \mathrm{T}=80^{\circ} \mathrm{C}$, MW irradiation (10 W power), $\mathrm{t}=0.5 \mathrm{~h}$. ${ }^{\mathrm{b}}$ Moles of acetophenone per $100 \mathrm{~mol}$ of 1-phenylethanol; selectivity $>99 \%$.

Attempts to promote the catalytic performance of 1, 3 and 5 MNPs systems by adding the organic radical TEMPO ((2,2,6,6-tetramethylpiperidin-1-yl)oxidanyl) (2.5\% mol vs. 1-phenylethanol) were unsuccessful since no obvious changes in the obtained yield of acetophenone were recorded. The addition of known C.and O-radical traps, $\mathrm{CBrCl}_{3}$ and $\mathrm{Ph}_{2} \mathrm{NH}(2.5 \% \mathrm{~mol}$ vs. 1-phenylethanol), respectively, resulted in a serious lack of product formation (below $1 \%$ of acetophenone), proving the radical nature of the catalytic system using $t$ - $\mathrm{BuOOH}[42,43]$. On the basis of this results the free radical mechanism illustrated in Scheme 2 is proposed. The oxidation of 1-phenylethanol is mediated by tert-butylperoxyl and tert-butoxyl radicals $[36,41,44]$ that can be produced upon oxidation or reduction of $t$-BuOOH with the MNPs (catalyst), as shown in Equations (1) and (2) [45,46]. Either $t$-BuOO. or $t$ - $\mathrm{BuO}$ can perform $\mathrm{H}$-abstraction from the alcohol substrate. However, in a $t$ - $\mathrm{BuOOH}$ rich medium it is more likely that $t$ - $\mathrm{BuO}$ - transforms into $t$ - $\mathrm{BuOO}$, upon $\mathrm{H}$-abstraction from the peroxide $[47,48]$. Hence, $t$-BuOO radical should be the main responsible one for the free-radical $\mathrm{H}$-abstraction from the substrate. 


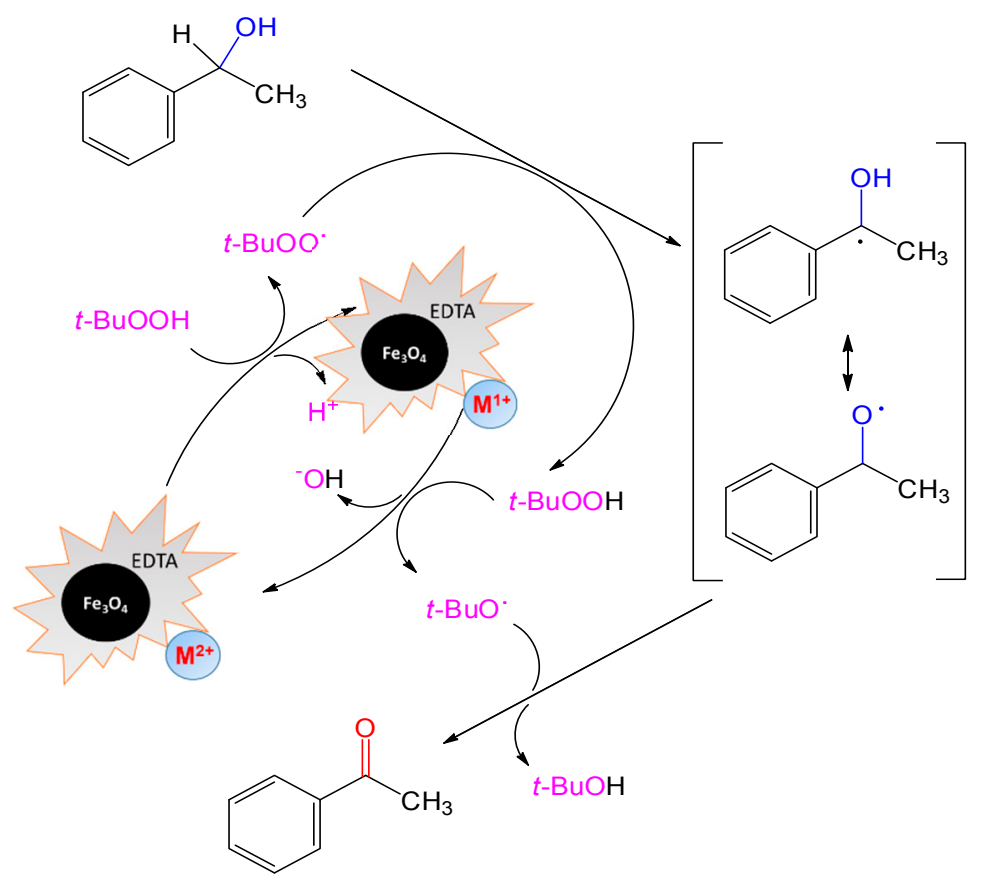

Scheme 2. Proposed mechanism for $\mathrm{Fe}_{3} \mathrm{O}_{4} @ E D T A-\mathrm{M}^{2+}\left[\mathrm{M}^{2+}=\mathrm{Mn}^{2+}(\mathbf{1}), \mathrm{Fe}^{2+}(2), \mathrm{Co}^{2+}(3), \mathrm{Ni}^{2+}\right.$ (4) or $\left.\mathrm{Cu}^{2+}(5)\right]$ MNPs catalyzed oxidation of 1-phenylethanol to acetophenone in the presence $t$ - $\mathrm{BuOOH}$.

$$
\begin{gathered}
\mathrm{Fe}_{3} \mathrm{O}_{4} @ \mathrm{EDTA}^{2+}+t-\mathrm{BuOOH} \rightarrow \mathrm{Fe}_{3} \mathrm{O}_{4} @ \mathrm{EDTA}^{+} \mathrm{M}^{+}+t-\mathrm{BuOO}+\mathrm{H}^{+} \\
\mathrm{Fe}_{3} \mathrm{O}_{4} @ \mathrm{EDTA} \mathrm{M}^{+}+t-\mathrm{BuOOH}+\mathrm{H}^{+} \rightarrow \mathrm{Fe}_{3} \mathrm{O}_{4} @ \mathrm{EDTA}^{2} \mathrm{M}^{2+}+t-\mathrm{BuO}+\mathrm{H}_{2} \mathrm{O}
\end{gathered}
$$

The use of a conventional heating (oil bath) method was evaluated as it is shown in Figure 8, Figures S11 (Supplementary Materials) and S12 (Supplementary Materials) for 1, 3 and 5 MNPs, respectively. In general, the activity was enhanced upon increasing the temperature up to $110{ }^{\circ} \mathrm{C}$. For $5 \mathrm{MNPs}$ full conversion (99\% yield of acetophenone) is reached at $6 \mathrm{~h}$ and $110{ }^{\circ} \mathrm{C}$, in comparison with $77 \%\left(80^{\circ} \mathrm{C}\right)$ and $79.2 \%\left(140^{\circ} \mathrm{C}\right)$ yields obtained at the same reaction time. The second and third most active catalytic systems at $110^{\circ} \mathrm{C}$ were 1 and $3 \mathrm{MNPs}$, which produce acetophenone in a yield of $95 \%$ and $85 \%$, respectively, after $6 \mathrm{~h}$. Screening at the highest temperature, $140{ }^{\circ} \mathrm{C}$, resulted in a slightly increase of activity till $1 \mathrm{~h}$ reaction time, whereafter the corresponding yield of acetophenone was lower than at $110{ }^{\circ} \mathrm{C}$ and even lower than at $80^{\circ} \mathrm{C}$ after $15 \mathrm{~h}$. The increase in activity with temperature is expected on kinetic basis and can enhance the formation of radical species $(t-\mathrm{BuOO} \cdot$ and $t$-BuO) that will further interact with the alcohol substrate and promote the oxidation reaction $[6,7,41]$. However, at $140^{\circ} \mathrm{C}$, overoxidation and/or decomposition of the oxidant can result in a lower yield of acetophenone.

The influence of the heating mode was evaluated by comparison of the yields of acetophenone formed under the same reaction conditions using the traditional heating (oil bath) or MW-induced heating at $110{ }^{\circ} \mathrm{C}$ for $\mathbf{1}$ MNPs (Figure 9) and 5 MNPs (Figure S13, Supplementary Materials) catalytic systems. Through MW-induced heating, full conversion of 1-phenylethanol was reached must faster $(3 \mathrm{~h})$ than in the experiments with traditional heating (ca. $6 \mathrm{~h}$ ). Moreover, for instance, at the reaction time of $2 \mathrm{~h}$, a much higher yield of acetophenone was attained using MW irradiation, 95\% (1 MNPs) and 93\% (5 MNPs), than heating with an oil bath, 68\% (1 MNPs) and 71\% (5 MNPs). 


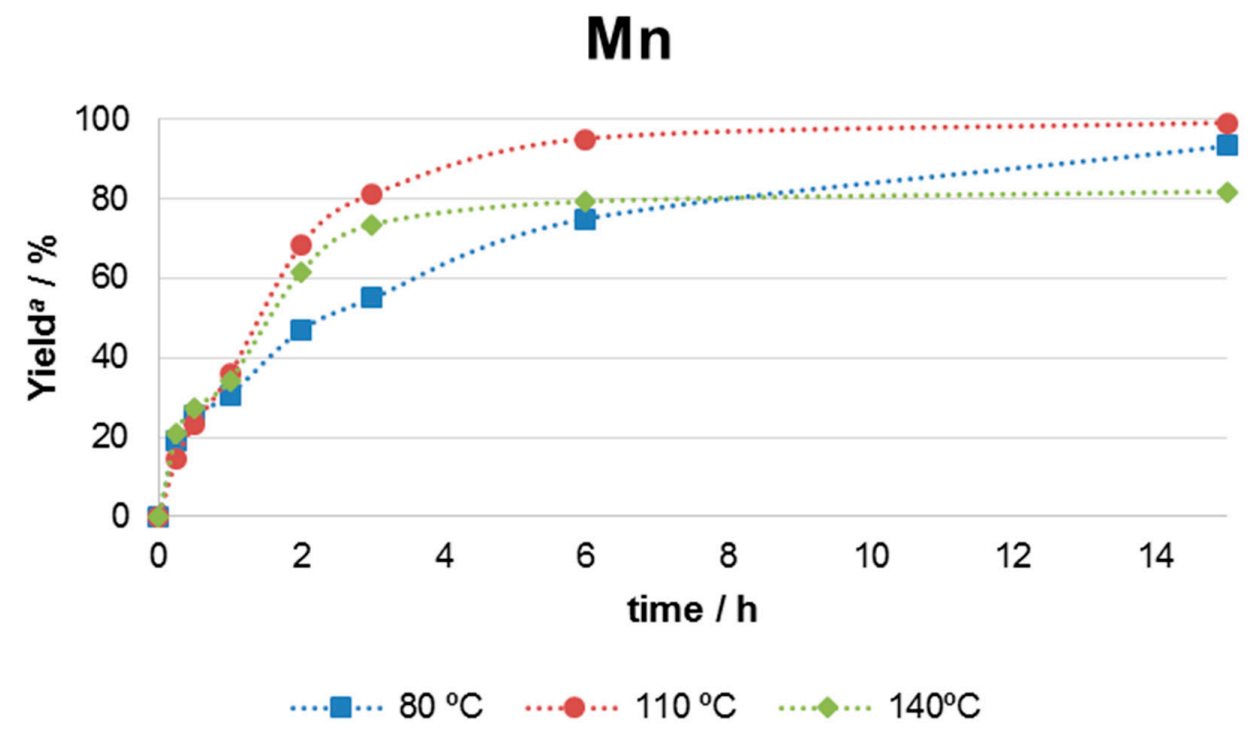

Figure 8. Acetophenone yields vs. reaction time in the solvent-free traditional heated oxidation of 1-phenylethanol using $\mathrm{Fe}_{3} \mathrm{O}_{4} @ E D T A-\mathrm{Mn}^{2+}(\mathbf{1})$ as catalyst. Reaction conditions: catalyst (30 mg), 1-phenylethanol $(2.5 \mathrm{mmol}), t-\mathrm{BuOOH}$ aq. $70 \%$ (5.0 mmol). ${ }^{a}$ Moles of acetophenone per $100 \mathrm{~mol}$ of 1-phenylethanol (GC yield), >99\% selectivity.

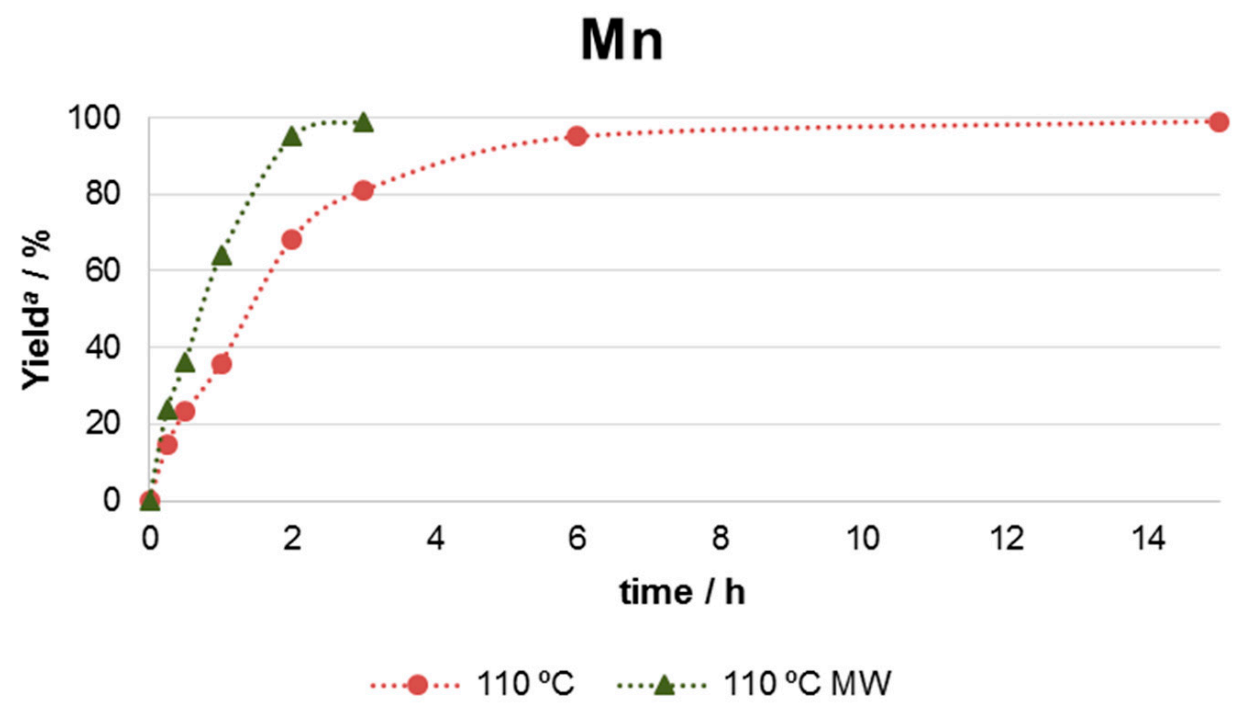

Figure 9. Acetophenone yields vs. reaction time in the solvent-free traditional heated and $\mathrm{MW}$-assisted oxidation of 1-phenylethanol using $\mathrm{Fe}_{3} \mathrm{O}_{4} @$ EDTA- $\mathrm{Mn}^{2+}(\mathbf{1})$ as catalyst. Reaction conditions: catalyst (30 mg), 1-phenylethanol (2.5 mmol), $t$-BuOOH aq. 70\% $(5.0 \mathrm{mmol}), \mathrm{T}=110^{\circ} \mathrm{C}$. ${ }^{a}$ Moles of acetophenone per $100 \mathrm{~mol}$ of alcohol substrate (GC yield), >99\% selectivity.

Under the achieved optimized reaction conditions the scope of alcohol substrates was tested using 1 MNPs as catalyst (Table 2). All the alcohol substrates were oxidized to the corresponding aldehydes or ketones in a selectivity manner $(>99 \%)$. The overoxidation of aldehydes to the corresponding carboxylic acids or other competing reactions was not observed. Secondary aromatic alcohols (Table 2, entries 1 and 3) were oxidized in a larger extent than primary ones (Table 2, entries 2 and 4) due the higher stability of the radical organic species formed upon $\mathrm{H}$ abstraction. Primary alcohols can exhibit lower steric hindrance, but the lower radical intermediate stability accounts for the lower reactivity. 
Table 2. Solvent-free MW-assisted oxidation of various alcohols using 1 MNPs as catalyst ${ }^{\text {a }}$.

\begin{tabular}{llll}
\hline Entry & Substrate & Product & Yield $\mathbf{b} / \%$ \\
\hline & Acetophenone & \\
\hline & & & \\
& & &
\end{tabular}

(1,2-Cyclohexanedione

a Reaction conditions: catalyst $(30 \mathrm{mg})$, alcohol substrate $(2.5 \mathrm{mmol}), t$-BuOOH aq. $70 \%$ (5.0 mmol), MW irradiation (10 W power), $\mathrm{T}=110^{\circ} \mathrm{C}, \mathrm{t}=2 \mathrm{~h} .{ }^{\mathrm{b}}$ Moles of aldehyde or ketone per $100 \mathrm{~mol}$ of alcohol substrate; selectivity $>99 \%$. ' Selectivity ca. $92 \%$.

Secondary alicyclic alcohols were oxidized with yields over than 95\% (Table 2, entries 5-8), with cyclooctanol exhibiting a slightly higher reactivity than the other alcohols with shorter carbon rings with a lower capacity to form radical intermediate structures [41]. Moreover, camphor is produced 
in a higher yield from isoborneol (90\%) than fenchaldehyde from fenchyl alcohol $(67 \%)$ (Table 2, entries 9 and 10), conceivably on account of steric effects.

The catalytic behavior of 1 MNPs was extended to the oxidation of two isomeric diols (Table 2, entries 11-12), 1,2- and 1,4-cyclohexanediols. The vicinal diketone (91.3\%) was formed in higher yield than the 1,4-diketone (73.2\%). This tendency was expected in vic-diols [41]. Excellence in selectivity was not accomplished in diols oxidation (ca. 92\%), due the formation of other species, such as hydroxyl ketones, or even hydroxyoxepanones (Baeyer-Villiger mechanism type) in harmony with other reports $[41,49,50]$.

Recycling experiments were carried out under the same optimized conditions using 1 MNPs (Figure 10). The catalyst is magnetically recovered easily after the reaction, washed, dried and then added to a new reaction step up. Therefore, further operations, such as filtration or centrifugation, were dispensable. The catalyst was recycled 5 times in the oxidation of 1-phenylethanol without a considerable loss of activity. In order to verify the absence of leaching during the oxidation reaction the following test was performed: after $30 \mathrm{~min}$ of reaction the $1 \mathrm{MNPs}$ were magnetically removed from the reaction solution yielding $26 \%$ of acetophenone. The reaction was then left to proceed without the catalyst during more $6 \mathrm{~h}$ and no significant increase of yield was observed.

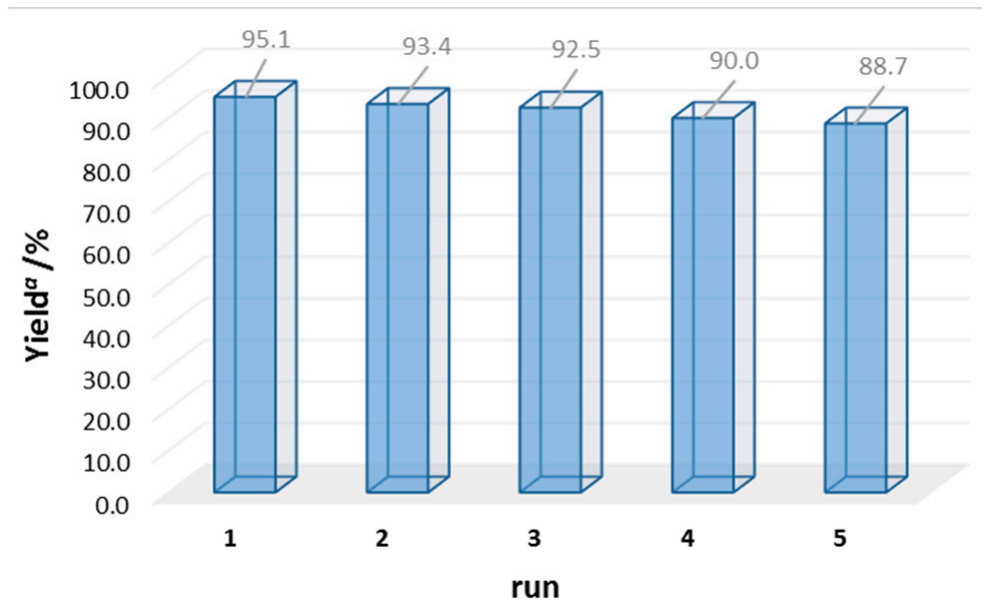

Figure 10. Solvent-free MW-assisted oxidation of 1-phenylethanol to acetophenone using $\mathrm{Fe}_{3} \mathrm{O}_{4} @$ EDTA-Mn ${ }^{2+}(\mathbf{1})$ as catalyst before and after reaction (up to 5 recycles). Reaction conditions: catalyst $(30 \mathrm{mg}), 1$-phenylethanol $(2.5 \mathrm{mmol}), \mathrm{t}-\mathrm{BuOOH}$ aq. $70 \%(5.0 \mathrm{mmol}), \mathrm{T}=110{ }^{\circ} \mathrm{C}, \mathrm{t}=2 \mathrm{~h}$.

a Moles of acetophenone per $100 \mathrm{~mol}$ of alcohol substrate (GC yield), >99\% selectivity.

In comparison with other reported magnetic-based catalysts bearing first-row transition-metal(s) employed for the oxidation of 1-phenylethanol, the prepared $\mathbf{1}$ and $\mathbf{5}$ MNPs are more efficient (Table 3). Most of the already-reported catalytic systems from Table 3 present high selectivity for acetophenone. However, in view of efficiency, in which yield and reaction time are key factors, just cobalt-chitosan (Table 3, entry 5) seems to be comparable with our 1- and 5-based catalytic systems. Besides the use of lower temperature $\left(80^{\circ} \mathrm{C}\right)$ and $\mathrm{O}_{2}$ as oxygen source, the methodology with cobalt-chitosan requires the use of a salt in stoichiometric amount and an organic solvent. In that sense, our synthetic protocol constitutes a better alternative since there is no need for solvent or additives. Moreover, despite the higher temperature used $\left(120^{\circ} \mathrm{C}\right.$ vs. $\left.80^{\circ} \mathrm{C}\right)$, MW-irradiation consumes much lower energy than conventional heating. 
Table 3. Comparison of $\mathbf{1}$ and $\mathbf{5}$ MNPs with other magnetic-based first-row transition-metal catalysts for the oxidation of 1-phenylethanol to acetophenone.

\begin{tabular}{|c|c|c|c|c|c|}
\hline Entry & Catalyst & Reaction Conditions & Yield a $\%$ & Selectivity $\mathrm{b} / \%$ & Reference \\
\hline 1 & $\mathrm{Fe}_{3} \mathrm{O}_{4}$ & $\mathrm{O}_{2}, 80^{\circ} \mathrm{C}, 18 \mathrm{~h}$, toluene & 76 & 100 & [51] \\
\hline 2 & $\mathrm{Fe}_{3} \mathrm{O}_{4}$ & $t$-BuOOH, MW $120^{\circ} \mathrm{C}, 2 \mathrm{~h}$ & 51.2 & $>99$ & [14] \\
\hline 3 & Cu-FPZ & $\mathrm{NaHCO}_{3}, \mathrm{TEMPO}, \mathrm{O}_{2}, 60^{\circ} \mathrm{C}, 12 \mathrm{~h}$, acetonitrile & 54 & 99 & [52] \\
\hline 4 & $\mathrm{Fe}_{3} \mathrm{O}_{4} @ \mathrm{Cu}_{3}(\mathrm{BTC})_{2}$ & $\mathrm{Na}_{2} \mathrm{CO}_{3}, \mathrm{TEMPO}, \mathrm{O}_{2}, 75^{\circ} \mathrm{C}, 12 \mathrm{~h}$, acetonitrile & 7 & $>99$ & [53] \\
\hline 5 & Cobalt-chitosan & $\mathrm{K}_{2} \mathrm{CO}_{3}, \mathrm{O}_{2}, 80^{\circ} \mathrm{C}, 4 \mathrm{~h}$, $p$-xylene & 95 & 100 & [54] \\
\hline 6 & Mn@MNP & $t$-BuOOH, $110^{\circ} \mathrm{C}, 4 \mathrm{~h}$, dimethyl sulfoxide & 4 & 86 & [55] \\
\hline 7 & $\mathrm{Fe}_{3} \mathrm{O}_{4} @ \mathrm{mSiO}_{2} / \mathrm{NH}-\mathrm{PV}_{2} \mathrm{~W}$ & $\mathrm{H}_{2} \mathrm{O}_{2}, 80^{\circ} \mathrm{C}, 8 \mathrm{~h}$, toluene & 40 & 99 & [56] \\
\hline 9 & $\mathrm{Fe}_{3} \mathrm{O}_{4} @$ EDTA-Cu ${ }^{2+}(5)$ & $t$-BuOOH, MW $110^{\circ} \mathrm{C}, 2 \mathrm{~h}$ & 93.3 & $>99$ & This work \\
\hline
\end{tabular}

${ }^{a}$ Moles of acetophenone per $100 \mathrm{~mol}$ of 1-phenylethanol). ${ }^{\mathrm{b}}$ Selectivity based on acetophenone (desired product per $100 \mathrm{~mol}$ of converted substrate). $\mathrm{Cu}-\mathrm{FPZ}=$ copper-doped $\mathrm{Fe}_{3} \mathrm{O}_{4} @$ poly(4-vinylpyridine-codivinylbenzene)@ZIF-8. $\mathrm{Mn} @ \mathrm{MNP}=$ aminosalicylidene manganese complex bearing terminal alkynyl with azide-functionalized shell-core magnetic nanoparticles. $\mathrm{Fe}_{3} \mathrm{O}_{4} @ \mathrm{mSiO}_{2} / \mathrm{NH}-\mathrm{PV}_{2} \mathrm{~W}=$ divanadium-substituted Keggin phosphotungstic acid $\mathrm{H}_{5} \mathrm{PV}_{2} \mathrm{~W}_{10} \mathrm{O}_{40}$ on mesoporous silica coated $\mathrm{Fe}_{3} \mathrm{O}_{4}$ core-shell nanoparticles. TEMPO = organic radical, 2,2,6,6-tetramethylpiperidine 1-oxyl.

Our transition-metal EDTA functionalized magnetite nanocatalysts constitute an optimization of the magnetic ferrites previously reported by us [14]. Among the ferrite materials, magnetite exhibited the most promising chemo-physical properties, such as higher magnetization, turning it the easiest material to manipulate using an external magnet. The surface of $\mathrm{Fe}_{3} \mathrm{O}_{4}$ was functionalized by coating with EDTA. This transformation allowed limiting the aggregation effect between nanoparticles (Figure 3) that would reduce the available surface area. Therefore, a higher specific area was obtained meaning more active sites per unit mass able to catalyze the reaction. At the same time, the chelating atoms of EDTA, $\mathrm{N}$ and $\mathrm{O}$ allowed the complexation of transition ion metals on the surface of the nanoparticles (Figure 4) that served as active sites for alcohol oxidation (Scheme 2). Importantly, these improved features occur without loss of the magnetic properties (Figure 6). Therefore, the catalytic performance of EDTA functionalized materials allowed reaching full conversion of 1-phenylethanol what was not achievable with the previous reported transition metal ferrites [14] applying the same solvent-free MW-assisted oxidation methodology.

\section{Experimental Section}

\subsection{Materials and Instrumentation}

All the chemicals were obtained from commercial sources (Aldrich, Darmstadt, Germany) and used as received. Infrared spectra $\left(4000-400 \mathrm{~cm}^{-1}\right)$ were recorded on a Vertex 70 (Bruker) instrument in $\mathrm{KBr}$ pellets (Ettlingen, Germany). The catalytic tests under MW irradiation were performed in a focused microwave Anton Paar Monowave 300 reactor $(10 \mathrm{~W})$, using a $10 \mathrm{~mL}$ capacity reaction tube with a $13 \mathrm{~mm}$ internal diameter, fitted with a rotational system and an IR temperature detector.

The structural properties of synthesized nanoparticles were analyzed by powder X-ray diffraction (PXRD) (Bruker, Ettlingen, Germany) on a D8 Advance Bruker AXS (Bragg Brentano geometry) theta-2theta diffractometer using $\mathrm{Cu}(\mathrm{K} \alpha)$ radiation (wavelength: $1.5406 \AA$ ) and a secondary monochromator, operated at $40 \mathrm{kV}$ and $40 \mathrm{~mA}$ at room temperature in the range of $2 \theta$ from 10 to $80^{\circ}$ with a scan speed of $0.02^{\circ} / \mathrm{s}$. Aluminum sample holder was used.

The particle size and morphology of the surfaces of sample were analyzed by transmission electron microscopy (TEM) Hithachi 8100 (Austin, TX, USA) and scanning electron microscopy (SEM) Hithachi S2400 instrument (Austin, TX, USA) with Bruker light elements and energy-dispersive X-ray spectroscopy (EDS) detector (Austin, TX, USA). The samples were coated with Au-Pt in an ionization chamber.

Thermal gravimetric analysis (TGA) experiments (Perkin-Elmer, Waltham, MA, USA) were performed using a Perkin-Elmer Instrument system (STA6000) with a heating rate of $20^{\circ} \mathrm{C} \mathrm{min}^{-1}$ over a temperature range of $30-800{ }^{\circ} \mathrm{C}$ under flowing compressed dinitrogen atmosphere. 
Magnetic properties were studied using a cryo-free vibrating sample magnetometer (VSM) from Cryogenics (London, UK) that allows measurements in the temperature range of 2-320 K, under magnetic fields up to $100 \mathrm{kOe}(10$ Tesla), with sensitivity and reproducibility of the order 10-4 emu, depending on the field range and sweep rate.

For identification and quantification of the reaction species gas chromatographic (GC) measurements were carried out using a FISONS Instruments GC 8000 series gas chromatograph with a DB-624 (J\&W) capillary column (FID detector) and the Jasco-Borwin v.1.50 software (Jasco, Tokyo, Japan). The temperature of injection was $240{ }^{\circ} \mathrm{C}$. The initial temperature was maintained at $120^{\circ} \mathrm{C}$ for $1 \mathrm{~min}$, then raised $10{ }^{\circ} \mathrm{C} / \mathrm{min}$ to $200{ }^{\circ} \mathrm{C}$ and held at this temperature for $1 \mathrm{~min}$. Helium was used as the carrier gas. Reaction products were identified by comparison of their retention times with known reference compounds.

\subsection{Catalyst Preparation}

\subsubsection{Synthesis of $\mathrm{Fe}_{3} \mathrm{O}_{4} @ E D T A$}

The MNPs $\mathrm{Fe}_{3} \mathrm{O}_{4} @ E D T A-\mathrm{E}^{2+}\left[\mathrm{M}^{2+}=\mathrm{Mn}^{2+}(\mathbf{1}), \mathrm{Fe}^{2+}(2), \mathrm{Co}^{2+}(3), \mathrm{Ni}^{2+}(4), \mathrm{Cu}^{2+}(5)\right.$ or $\left.\mathrm{Zn}^{2+}(6)\right]$ were prepared by adaptation of a reported co-precipitation method (Scheme 3) [28]. Anhydrous $\mathrm{FeCl}_{3}$ $(1.6 \mathrm{~g}, 10 \mathrm{mmol})$ and $\mathrm{FeCl}_{2} \cdot 4 \mathrm{H}_{2} \mathrm{O}(1.0 \mathrm{~g}, 5 \mathrm{mmol})$ were dissolved in $100 \mathrm{~mL}$ deionized water. Ammonia solution (aq. $30 \% v / v)$ was added dropwise till the solution reached $\mathrm{pH}=12$ while stirring at $80{ }^{\circ} \mathrm{C}$. During the addition of aq. ammonia solution, EDTA (disodium salt dihydrate) solution $(1.1 \mathrm{~g}, 2 \mathrm{mmol}$ in $20 \mathrm{~mL}$ water) was added to this black suspension. The resulting black dispersion was continuously stirred for $1 \mathrm{~h}$ and then cooled down to room temperature and stirred for more $2 \mathrm{~h}$. The resulting precipitate, $\mathrm{Fe}_{3} \mathrm{O}_{4} @$ EDTA (0) MNPs, was isolated with the help of an auxiliary external magnet, and washed with deionized water three times.

\subsubsection{Functionalization of $\mathrm{Fe}_{3} \mathrm{O}_{4} @ E D T A$}

$50 \mathrm{~mL}$ water were added to 0 , then $\mathrm{MnCl}_{2} \cdot 4 \mathrm{H}_{2} \mathrm{O}(0.40 \mathrm{~g}, 2 \mathrm{mmol})$ and $\mathrm{Na}_{2} \mathrm{CO}_{3}(0.42 \mathrm{~g}, 4 \mathrm{mmol})$ were introduced to it and stirred at $40{ }^{\circ} \mathrm{C}$ for $6 \mathrm{~h}$. The suspension was refluxed for $2 \mathrm{~h}$. Finally, the $\mathrm{Fe}_{3} \mathrm{O}_{4} @$ EDTA-Mn ${ }^{2+}$ (1) MNPs were once again isolated with the help of an auxiliary external magnet, washed with deionized water and ethanol three times before being dried in an oven overnight.

The above process was extended to the synthesis of $\mathrm{Fe}_{3} \mathrm{O}_{4} @$ EDTA- $^{2+}\left(\mathrm{M}=\mathrm{Fe}^{2+}(2), \mathrm{Co}^{2+}(3)\right.$, $\mathrm{Ni}^{2+}(4), \mathrm{Cu}^{2+}(5)$ or $\left.\mathrm{Zn}^{2+}(6)\right)$ using the corresponding divalent metal chloride salts for that purpose.
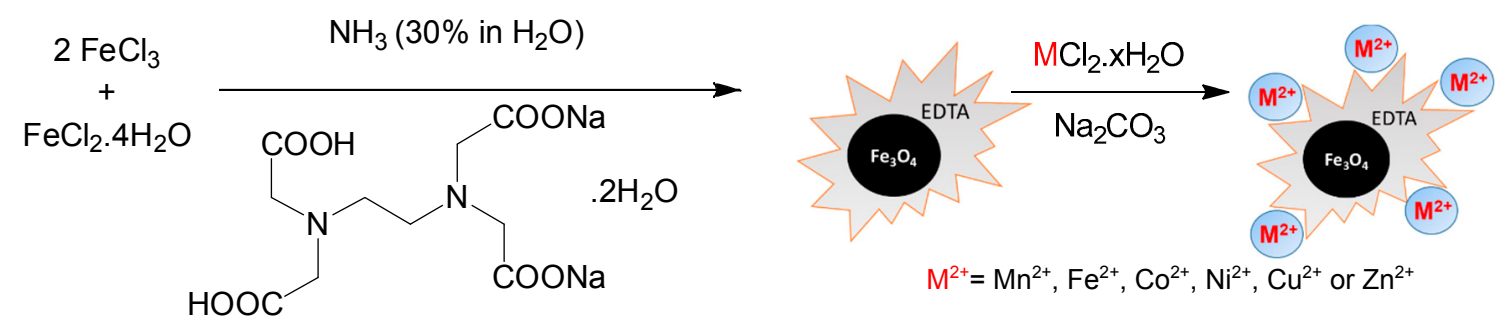

Scheme 3. Preparation of $\mathrm{Fe}_{3} \mathrm{O}_{4} @ E D T A-\mathrm{M}^{2+}\left[\mathrm{M}^{2+}=\mathrm{Mn}^{2+}(1), \mathrm{Fe}^{2+}(2), \mathrm{Co}^{2+}(3), \mathrm{Ni}^{2+}(4), \mathrm{Cu}^{2+}(5)\right.$ or $\left.\mathrm{Zn}^{2+}(6)\right]$ MNPs.

\subsection{General Procedure for the Peroxidative Oxidation of Alcohols}

In a typical experiment, the alcohol substrate $(2.5 \mathrm{mmol}), t-\mathrm{BuOOH}(70 \%$ in aqueous solution, $5.0 \mathrm{mmol}$ ) and catalyst 1-6 MNPs $(30 \mathrm{mg}$ ) were introduced to a cylindrical Pyrex tube with a stirring bar, which was then placed in the focused microwave reactor. In the (2,2,6,6-tetramethylpiperidine-1-yl)oxidanyl (TEMPO)-mediated experiments, TEMPO (62.5 $\mu \mathrm{mol}$, $2.5 \mathrm{~mol} \%$ vs. substrate) was added to the reaction mixture. The system was stirred and microwave (MW)-irradiated (10 W) for 15 to $180 \mathrm{~min}$ at $80-110^{\circ} \mathrm{C}$. After the reaction, the mixture was allowed 
to cool down to room temperature. $150 \mu \mathrm{L}$ of benzaldehyde (or cyclopentanone in benzyl alcohol oxidation) as internal standard and $2.5 \mathrm{~mL}$ of acetonitrile (to extract the substrate and the organic products from the reaction mixture) were added. The obtained mixture was stirred during $10 \mathrm{~min}$ and then a sample $(0.5 \mu \mathrm{L})$ was taken from the organic phase and analyzed by GC using the internal standard method, so the yield and selectivity of the reaction can be calculated.

\section{Conclusions}

We have introduced a novel straightforward protocol for a solvent-free MW-assisted selective catalytic oxidation of alcohols to their corresponding carbonyl compounds based on transition metals complexed on the surface of functionalized magnetite with EDTA. Among these prepared superparamagnetic nanoparticles (3-15 nm), $\mathrm{Fe}_{3} \mathrm{O}_{4} @$ EDTA-Mn ${ }^{2+}$ (1) and $\mathrm{Fe}_{3} \mathrm{O}_{4} @ E D T A-C u^{2+}$ (5) exhibited the highest activity as catalysts towards the oxidation of 1-phenylethanol using aq. $t$ - $\mathrm{BuOOH}$ at $110{ }^{\circ} \mathrm{C}$, reaching full conversion in just $3 \mathrm{~h}$ of reaction. Tests with radical traps suggest a free radical-based catalytic cycle.

The simple preparation of cheap and stable transition metal-based ferrites, the use of nontoxic and inexpensive materials, the absence of organic solvents, the low power (10 W) MW irradiation for heating, the easy separation and recovery of the catalysts from the reaction medium and the convenient magnetic recyclability of the catalyst constitute real advantages of the present catalytic systems.

The application of these MNPs to different organic reactions is currently under investigation in our laboratory.

Supplementary Materials: The following are available online at www.mdpi.com/2073-4344/7/11/335/s1, Figure S1. FT-IR spectrum of $\mathrm{Fe}_{3} \mathrm{O}_{4}$ and 0-6 MNPs in the range of $4000-400 \mathrm{~cm}^{-1}$. Figure S2. X-ray diffraction patterns of $\mathrm{Fe}_{3} \mathrm{O}_{4}$ and 0-6 MNPs (aluminum sample holder XRD peak marked *). Figure S3. EDS spectrum of $\mathrm{Fe}_{3} \mathrm{O}_{4} @$ EDTA (0) MNPs. Figure S4. EDS spectrum of $\mathrm{Fe}_{3} \mathrm{O}_{4} @ E D T A-\mathrm{Mn}^{2+}$ (1) MNPs. Figure S5. EDS spectrum of $\mathrm{Fe}_{3} \mathrm{O}_{4} @$ EDTA-Fe ${ }^{2+}$ (2) MNPs. Figure S6. EDS spectrum of $\mathrm{Fe}_{3} \mathrm{O}_{4} @ E D T A-\mathrm{Co}^{2+}$ (3) MNPs. Figure S7. EDS spectrum of $\mathrm{Fe}_{3} \mathrm{O}_{4} @ E$ EDTA-Ni ${ }^{2+}(4)$ MNPs. Figure S8. EDS spectrum of $\mathrm{Fe}_{3} \mathrm{O}_{4} @ E D T A-\mathrm{Cu}^{2+}(5)$ MNPs. Figure S9. EDS spectrum of $\mathrm{Fe}_{3} \mathrm{O}_{4} @ E D T A-\mathrm{Zn}^{2+}(6)$ MNPs. Figure S10. TGA analysis of $\mathrm{Fe}_{3} \mathrm{O}_{4}$ and 0-6 MNPs. Figure S11. Acetophenone yields vs. reaction time in the solvent-free traditional heating oxidation of 1-phenylethanol using $\mathrm{Fe}_{3} \mathrm{O}_{4} @$ EDTA- $\mathrm{Co}^{2+}(3)$ as catalyst. Figure S12. Acetophenone yields vs. reaction time in the solvent-free traditional heating oxidation of 1-phenylethanol using $\mathrm{Fe}_{3} \mathrm{O}_{4} @ E D T A-\mathrm{Cu}^{2+}(5)$ as catalyst. Figure S13. Acetophenone yields vs. reaction time in the solvent-free traditional heating and MW-assisted oxidation of 1-phenylethanol using $\mathrm{Fe}_{3} \mathrm{O}_{4} @$ EDTA-Cu${ }^{2+}(5)$ as catalyst. Table S1. Obtained EDS data related to $\mathrm{Fe}_{3} \mathrm{O}_{4} @$ EDTA (0) MNPs. Table S2. Obtained EDS data related to $\mathrm{Fe}_{3} \mathrm{O}_{4} @ E D T A-\mathrm{Mn}^{2+}$ (1) MNPs. Table S3. Obtained EDS data related to $\mathrm{Fe}_{3} \mathrm{O}_{4} @ E D T A-\mathrm{Fe}^{2+}$ (2) MNPs. Table S4. Obtained EDS data related to $\mathrm{Fe}_{3} \mathrm{O}_{4} @ E D T A-\mathrm{Co}^{2+}$ (2) MNPs. Table S5. Obtained EDS data related to $\mathrm{Fe}_{3} \mathrm{O}_{4} @$ EDTA-Ni ${ }^{2+}$ (4) MNPs. Table S6. Obtained EDS data related to $\mathrm{Fe}_{3} \mathrm{O}_{4} @$ EDTA-Cu ${ }^{2+}(5)$ MNPs. Table S7. Obtained EDS data related to $\mathrm{Fe}_{3} \mathrm{O}_{4} @ E D T A-Z^{2+}(6)$ MNPs.

Acknowledgments: This work has been supported by the Foundation for Science and Technology (FCT), Portugal (UID/QUI/00100/2013, PTDC/QEQ-ERQ/1648/2014 and PTDC/QEQ-QIN/3967/2014 projects). NMRM express gratitude to FCT for the PhD CATSUS fellowship (SFRH/BD/52371/2013). Work was also supported by project CICECO-Aveiro Institute of Materials, POCI-01-0145-FEDER-007679 (FCT Ref. UID/CTM/50011/2013), financed by national funds through the FCT/MEC and when appropriate co-financed by FEDER under the PT2020 Partnership Agreement. The authors thank I. Nogueira for the SEM analysis of MicroLab IST.

Author Contributions: Luísa M. D. R. S. Martins conceived the concept. Nuno M. R. Martins designed and performed the experiments. Luísa M. D. R. S. Martins analyzed the data. Carlos O. Amorim and Vitor S. Amaral performed the VSM studies. Luísa M. D. R. S. Martins and Armando J. L. Pombeiro provided the means needed for the realization of this work. All the authors contributed to the writing, read and approved the manuscript.

Conflicts of Interest: The authors declare no conflict of interest.

\section{References}

1. Bäckvall, J.E. Modern Oxidation Methods; Wiley: Hoboken, NJ, USA, 2006.

2. Tojo, G.; Fernandez, M.I. Oxidation of Alcohols to Aldehydes and Ketones: A Guide to Current Common Practice; Springer: Berlin, Germnay, 2006. 
3. Parmeggiani, C.; Cardona, F. Transition metal based catalysts in the aerobic oxidation of alcohols. Green Chem. 2012, 14, 547-564. [CrossRef]

4. González-Arellano, C.; Campelo, J.M.; Macquarrie, D.J.; Marinas, J.M.; Romero, A.A.; Luque, R. Efficient microwave oxidation of alcohols using low-loaded supported metallic iron nanoparticles. ChemSusChem 2008, 1, 746-750. [CrossRef] [PubMed]

5. Mahyari, M.; Shaabani, A. Graphene oxide-iron phthalocyanine catalyzed aerobic oxidation of alcohols. Appl. Catal. A 2014, 469, 524-531. [CrossRef]

6. Karabach, Y.Y.; Kopylovich, M.N.; Mahmudov, K.T.; Pombeiro, A.J.L. Microwave-assisted catalytic oxidation of alcohols to carbonyl compounds. In Advances in Organometallic Chemistry and Catalysis; John Wiley \& Sons, Inc.: Hoboken, NJ, USA, 2013; pp. 233-245.

7. Kopylovich, M.N.; Ribeiro, A.P.C.; Alegria, E.C.B.A.; Martins, N.M.R.; Martins, L.M.D.R.S.; Pombeiro, A.J.L. Chapter three-Catalytic oxidation of alcohols: Recent advances. In Advances in Organometallic Chemistry; Pedro, J.P., Ed.; Academic Press: Cambridge, MA, USA, 2015; Volume 63, pp. 91-174.

8. Polshettiwar, V.; Varma, R.S. Green chemistry by nano-catalysis. Green Chem. 2010, 12, 743-754. [CrossRef]

9. Polshettiwar, V.; Luque, R.; Fihri, A.; Zhu, H.; Bouhrara, M.; Basset, J.-M. Magnetically recoverable nanocatalysts. Chem. Rev. 2011, 111, 3036-3075. [CrossRef] [PubMed]

10. Albonetti, S.; Mazzoni, R.; Cavani, F. Chapter 1 homogeneous, heterogeneous and nanocatalysis. In Transition Metal Catalysis in Aerobic Alcohol Oxidation; The Royal Society of Chemistry: London, UK, 2015; pp. 1-39.

11. Ghandoor, H.E.; Zidan, H.M.; Khalil, M.M.H.; Ismail, M.I.M. Synthesis and some physical properties of magnetite $\left(\mathrm{Fe}_{3} \mathrm{O}_{4}\right)$ nanoparticles. Int. J. Electrochem. Sci. 2012, 7, 5734-5745.

12. Maaz, K.; Mumtaz, A.; Hasanain, S.K.; Ceylan, A. Synthesis and magnetic properties of cobalt ferrite $\left(\mathrm{CoFe}_{2} \mathrm{O}_{4}\right)$ nanoparticles prepared by wet chemical route. J. Magn. Magn. Mater. 2007, 308, $289-295$. [CrossRef]

13. Deng, H.; Li, X.; Peng, Q.; Wang, X.; Chen, J.; Li, Y. Monodisperse magnetic single-crystal ferrite microspheres. Angew. Chem. Int. Ed. 2005, 44, 2782-2785. [CrossRef] [PubMed]

14. Martins, N.; Martins, L.; Amorim, C.; Amaral, V.; Pombeiro, A. Solvent-free microwave-induced oxidation of alcohols catalyzed by ferrite magnetic nanoparticles. Catalysts 2017, 7, 222. [CrossRef]

15. Banerjee, S.S.; Chen, D.-H. Fast removal of copper ions by gum arabic modified magnetic nano-adsorbent. J. Hazard. Mater. 2007, 147, 792-799. [CrossRef] [PubMed]

16. Chang, Y.-C.; Chen, D.-H. Preparation and adsorption properties of monodisperse chitosan-bound $\mathrm{Fe}_{3} \mathrm{O}_{4}$ magnetic nanoparticles for removal of $\mathrm{Cu}(\mathrm{II})$ ions. J. Colloid Interface Sci. 2005, 283, 446-451. [CrossRef] [PubMed]

17. Liu, J.-F.; Zhao, Z.-S.; Jiang, G.-B. Coating $\mathrm{Fe}_{3} \mathrm{O}_{4}$ magnetic nanoparticles with humic acid for high efficient removal of heavy metals in water. Environ. Sci. Technol. 2008, 42, 6949-6954. [CrossRef] [PubMed]

18. Huang, S.-H.; Chen, D.-H. Rapid removal of heavy metal cations and anions from aqueous solutions by an amino-functionalized magnetic nano-adsorbent. J. Hazard. Mater. 2009, 163, 174-179. [CrossRef] [PubMed]

19. Naeimi, H.; Mohamadabadi, S. Sulfonic acid-functionalized silica-coated magnetic nanoparticles as an efficient reusable catalyst for the synthesis of 1-substituted 1h-tetrazoles under solvent-free conditions. Dalton Trans. 2014, 43, 12967-12973. [CrossRef] [PubMed]

20. Habibi, D.; Faraji, A.R. Synthesis, characterization and application of a nano-manganese-catalyst as an efficient solid catalyst for solvent free selective oxidation of ethylbenzene, cyclohexene, and benzylalcohol. Appl. Surf. Sci. 2013, 276, 487-496. [CrossRef]

21. Azgomi, N.; Mokhtary, M. Nano- $\mathrm{Fe}_{3} \mathrm{O}_{4} @ \mathrm{SiO}_{2}$ supported ionic liquid as an efficient catalyst for the synthesis of 1,3-thiazolidin-4-ones under solvent-free conditions. J. Mol. Catal. A 2015, 398, 58-64. [CrossRef]

22. Jiang, S.; Yan, J.; Habimana, F.; Ji, S. Preparation of magnetically recyclable MIL-53(Al)@SiO $@_{2} \mathrm{Fe}_{3} \mathrm{O}_{4}$ catalysts and their catalytic performance for friedel-crafts acylation reaction. Catal. Today 2016, 264, 83-90. [CrossRef]

23. Esmaeilpour, M.; Javidi, J.; Nowroozi Dodeji, F.; Mokhtari Abarghoui, M. Facile synthesis of 1and 5-substituted 1h-tetrazoles catalyzed by recyclable ligand complex of Copper(ii) supported on superparamagnetic $\mathrm{Fe}_{3} \mathrm{O}_{4} @ \mathrm{SiO}_{2}$ nanoparticles. J. Mol. Catal. A 2014, 393, 18-29. [CrossRef]

24. Kakavandi, B.; Takdastan, A.; Jaafarzadeh, N.; Azizi, M.; Mirzaei, A.; Azari, A. Application of $\mathrm{Fe}_{3} \mathrm{O}_{4} @ \mathrm{C}$ catalyzing heterogeneous uv-fenton system for tetracycline removal with a focus on optimization by a response surface method. J. Photochem. Photobiol. A 2016, 314, 178-188. [CrossRef] 
25. Fan, W.; Gao, W.; Zhang, C.; Tjiu, W.W.; Pan, J.; Liu, T. Hybridization of graphene sheets and carbon-coated $\mathrm{Fe}_{3} \mathrm{O}_{4}$ nanoparticles as a synergistic adsorbent of organic dyes. J. Mater. Chem. 2012, 22, 25108-25115. [CrossRef]

26. Zhang, D.-H.; Li, G.-D.; Li, J.-X.; Chen, J.-S. One-pot synthesis of Ag-Fe $\mathrm{O}_{4}$ nanocomposite: A magnetically recyclable and efficient catalyst for epoxidation of styrene. Chem. Commun. 2008, 29, 3414-3416. [CrossRef] [PubMed]

27. Liu, Y.; Chen, M.; Hao, Y. Study on the adsorption of $\mathrm{Cu}(\mathrm{II})$ by edta functionalized $\mathrm{Fe}_{3} \mathrm{O}_{4}$ magnetic nano-particles. Chem. Eng. J. 2013, 218, 46-54. [CrossRef]

28. Azizi, K.; Karimi, M.; Nikbakht, F.; Heydari, A. Direct oxidative amidation of benzyl alcohols using EDTA@Cu(II) functionalized superparamagnetic nanoparticles. Appl. Catal. A 2014, 482, 336-343. [CrossRef]

29. Azizi, K.; Karimi, M.; Heydari, A. Oxidative coupling of formamides with $\beta$-dicarbonyl compounds and the synthesis of 2-aminobenzothiazole using $\mathrm{Cu}(\mathrm{II})$-functionalized $\mathrm{Fe}_{3} \mathrm{O}_{4}$ nanoparticles. Tetrahedron Lett. 2015, 56, 812-816. [CrossRef]

30. Spargo, P.L. Microwave assisted organic synthesis edited by J. P. Tierney and P. Lidstrom. Blackwell publishing: Oxford. 2005. 280 pp. £89.50. ISBN 1-4051-1560-2. (Also published by CRC Press in USA and Canada, ISBN 0-8493-2371-1.). Organ. Process Res. Dev. 2005, 9, 697. [CrossRef]

31. Dallinger, D.; Kappe, C.O. Microwave-assisted synthesis in water as solvent. Chem. Rev. 2007, 107, $2563-2591$. [CrossRef] [PubMed]

32. Liu, X.; An, S.; Shi, W.; Yang, Q.; Zhang, L. Microwave-induced catalytic oxidation of malachite green under magnetic Cu-ferrites: New insight into the degradation mechanism and pathway. J. Mol. Catal. A 2014, 395, 243-250. [CrossRef]

33. Roy, S.; Ghose, J. Effect of polymer matrix on the phase transitions of $\mathrm{CuFe}_{2} \mathrm{O}_{4}$. J. Solid State Chem. 1999, 144, 159-162. [CrossRef]

34. De la Hoz, A.; Diaz-Ortiz, A.; Moreno, A. Microwaves in organic synthesis. Thermal and non-thermal microwave effects. Chem. Soc. Rev. 2005, 34, 164-178. [CrossRef] [PubMed]

35. Kappe, C.O.; Dallinger, D.; Murphree, S.S. Experimental protocols. In Practical Microwave Synthesis for Organic Chemists; Wiley-VCH Verlag GmbH \& Co. KGaA: Weinheim, Germany, 2009; pp. 203-290.

36. Nasani, R.; Saha, M.; Mobin, S.M.; Martins, L.M.D.R.S.; Pombeiro, A.J.L.; Kirillov, A.M.; Mukhopadhyay, S. Copper-organic frameworks assembled from in situ generated 5-(4-pyridyl)tetrazole building blocks: Synthesis, structural features, topological analysis and catalytic oxidation of alcohols. Dalton Trans. 2014, 43, 9944-9954. [CrossRef] [PubMed]

37. Mahmudov, K.T.; Sutradhar, M.; Martins, L.M.D.R.S.; Guedes da Silva, M.F.C.; Ribera, A.; Nunes, A.V.M.; Gahramanova, S.I.; Marchetti, F.; Pombeiro, A.J.L. Mnii and cuii complexes with arylhydrazones of active methylene compounds as effective heterogeneous catalysts for solvent- and additive-free microwave-assisted peroxidative oxidation of alcohols. RSC Adv. 2015, 5, 25979-25987. [CrossRef]

38. Sutradhar, M.; Martins, L.M.D.R.S.; Guedes da Silva, M.F.C.; Pombeiro, A.J.L. Oxidovanadium complexes with tridentate aroylhydrazone as catalyst precursors for solvent-free microwave-assisted oxidation of alcohols. Appl. Catal. A 2015, 493, 50-57. [CrossRef]

39. Tăbăcaru, A.; Xhaferaj, N.; Martins, L.M.D.R.S.; Alegria, E.C.B.A.; Chay, R.S.; Giacobbe, C.; Domasevitch, K.V.; Pombeiro, A.J.L.; Galli, S.; Pettinari, C. Metal azolate/carboxylate frameworks as catalysts in oxidative and C-C coupling reactions. Inorgan. Chem. 2016, 55, 5804-5817. [CrossRef] [PubMed]

40. Karmakar, A.; Martins, L.M.D.R.S.; Hazra, S.; Guedes da Silva, M.F.C.; Pombeiro, A.J.L. Metal-organic frameworks with pyridyl-based isophthalic acid and their catalytic applications in microwave assisted peroxidative oxidation of alcohols and henry reaction. Cryst. Growth Des. 2016, 16, 1837-1849. [CrossRef]

41. Martins, N.M.R.; Mahmudov, K.T.; Guedes da Silva, M.F.C.; Martins, L.M.D.R.S.; Pombeiro, A.J.L. Copper(II) and Iron(III) complexes with arylhydrazone of ethyl 2-cyanoacetate or formazan ligands as catalysts for oxidation of alcohols. New J. Chem. 2016, 40, 10071-10083. [CrossRef]

42. Moiseeva, N.I.; Gekhman, A.E.; Minin, V.V.; Larin, G.M.; Bashtanov, M.E.; Krasnovskii, A.A.; Moiseev, I.I. Free radical/singlet dioxygen system under the conditions of catalytic hydrogen peroxide decomposition. Kinet. Catal. 2000, 41, 170-182. [CrossRef]

43. Mattalia, J.M.; Vacher, B.; Samat, A.; Chanon, M. Mechanistic investigation of the reaction between Alpha-sulfonyl carbanions and polyhalogenmethanes. Electron transfer versus polar pathways. J. Am. Chem. Soc. 1992, 114, 4111-4119. [CrossRef] 
44. Martins, L.M.D.R.S.; Alegria, E.C.B.A.; Smoleński, P.; Kuznetsov, M.L.; Pombeiro, A.J.L. Oxorhenium complexes bearing the water-soluble tris(pyrazol-1-yl)methanesulfonate, 1,3,5-triaza-7-phosphaadamantane or related ligands, as catalysts for the Baeyer-Villiger oxidation of ketones. Inorgan. Chem. 2013, 52, 4534-4546. [CrossRef] [PubMed]

45. Barton, D.H.R.; Le Gloahec, N.V.; Patin, H.; Launay, F. Radical chemistry of tert-butyl hydroperoxide (tbhp). Parts 1 and 2. Studies of the feiii-tbhp mechanism. New J. Chem. 1998, 22, 559-568. [CrossRef]

46. Kopylovich, M.N.; Mahmudov, K.T.; Silva, M.F.C.G.; Martins, L.M.D.R.S.; Kuznetsov, M.L.; Silva, T.F.S.; Fraústo da Silva, J.J.R.; Pombeiro, A.J.L. Trends in properties of para-substituted 3-(phenylhydrazo)pentane-2,4-diones. J. Phys. Organ. Chem. 2011, 24, 764-773. [CrossRef]

47. Minisci, F.; Fontana, F.; Araneo, S.; Recupero, F.; Banfi, S.; Quici, S. Kharasch and metalloporphyrin catalysis in the functionalization of alkanes, alkenes, and alkylbenzenes by t-buooh. Free radical mechanisms, solvent effect, and relationship with the gif reaction. J. Am. Chem. Soc. 1995, 117, 226-232. [CrossRef]

48. Boess, E.; Wolf, L.M.; Malakar, S.; Salamone, M.; Bietti, M.; Thiel, W.; Klussmann, M. Competitive hydrogen atom transfer to oxyl- and peroxyl radicals in the $\mathrm{Cu}$-catalyzed oxidative coupling of $\mathrm{N}$-aryl tetrahydroisoquinolines using tert-butyl hydroperoxide. ACS Catal. 2016, 6, 3253-3261. [CrossRef]

49. Ten Brink, G.J.; Arends, I.W.C.E.; Sheldon, R.A. The baeyer-villiger reaction: New developments toward greener procedures. Chem. Rev. 2004, 104, 4105-4124. [CrossRef] [PubMed]

50. Vafaeezadeh, M.; Mahmoodi Hashemi, M. Simple and green oxidation of cyclohexene to adipic acid with an efficient and durable silica-functionalized ammonium tungstate catalyst. Catal. Commun. 2014, 43, 169-172. [CrossRef]

51. Shaikh, M.; Satanami, M.; Ranganath, K.V.S. Efficient aerobic oxidation of alcohols using magnetically recoverable catalysts. Catal. Commun. 2014, 54, 91-93. [CrossRef]

52. Hou, J.; Luan, Y.; Yu, J.; Qi, Y.; Wang, G.; Lu, Y. Fabrication of hierarchical composite microspheres of copper-doped $\mathrm{Fe}_{3} \mathrm{O}_{4} @$ P4VP@ZIF-8 and their application in aerobic oxidation. New J. Chem. 2016, 40, 10127-10135. [CrossRef]

53. Li, J.; Gao, H.; Tan, L.; Luan, Y.; Yang, M. Superparamagnetic core-shell metal-organic framework $\mathrm{Fe}_{3} \mathrm{O}_{4} / \mathrm{Cu}_{3}$ (BTC) 2 microspheres and their catalytic activity in the aerobic oxidation of alcohols and olefins. Eur. J. Inorgan. Chem. 2016, 2016, 4906-4912. [CrossRef]

54. Shaabani, A.; BoroujenI, M.B.; Sangachin, M.H. Cobalt-chitosan: Magnetic and biodegradable heterogeneous catalyst for selective aerobic oxidation of alkyl arenes and alcohols. J. Chem. Sci. 2015, 127, 1927-1935. [CrossRef]

55. Zhou, Q.; Wan, Z.; Yuan, X.; Luo, J. A new magnetic nanoparticle-supported schiff base complex of manganese: An efficient and recyclable catalyst for selective oxidation of alcohols. Appl. Organomet. Chem. 2016, 30, 215-220. [CrossRef]

56. Dong, X.; Zhang, X.; Wu, P.; Zhang, Y.; Liu, B.; Hu, H.; Xue, G. Divanadium-substituted phosphotungstate supported on magnetic mesoporous silica nanoparticles as effective and recyclable catalysts for the selective oxidation of alcohols. ChemCatChem 2016, 8, 3680-3687. [CrossRef]

(C) 2017 by the authors. Licensee MDPI, Basel, Switzerland. This article is an open access article distributed under the terms and conditions of the Creative Commons Attribution (CC BY) license (http:// creativecommons.org/licenses/by/4.0/). 